\title{
VIP and PACAP analogs regulate therapeutic targets in high-risk neuroblastoma cells
}

Madryssa de BOISVILLIERS ${ }^{\mathrm{a}}$, Florian PERRIN ${ }^{\mathrm{a}}$, Salima HEBACHE ${ }^{\mathrm{a}}$, Annie-Claire BALANDRE $^{\mathrm{a}}$, Souheyla BENSALMA ${ }^{\mathrm{a}}$, Agnès GARNIER ${ }^{\mathrm{a}}$, David VAUDRY ${ }^{\mathrm{b}}$, Alain Fournier $^{\mathrm{c}}$, Franck FESTY ${ }^{\mathrm{d}}$, Jean-Marc MULLER ${ }^{\mathrm{a}}$ and Corinne CHADÉNEAU ${ }^{\mathrm{a}}$

${ }^{\mathrm{a} U n i v e r s i t e ́ ~ d e ~ P o i t i e r s ~-~ E ́ q u i p e ~ R e ́ c e p t e u r s, ~ R e ́ g u l a t i o n s ~ e t ~ C e l l u l e s ~ T u m o r a l e s ~(2 R C T) ~-~ P o ̂ l e ~}$ Biologie Santé - Bât. B36/B37 - UFR Sciences Fondamentales et Appliquées 1, rue Georges Bonnet, TSA 5110686073 POITIERS Cedex 9 (France)

${ }^{\mathrm{b}}$ Université de Rouen - INSERM U982 - Equipe Neuropeptides, survie neuronale et plasticité cellulaire - IRIB - UFR Sciences et Techniques - Place E. blondel, 76821 Mont-Saint-Aignan, (France)

${ }^{\mathrm{c}}$ INRS - Institut Armand-Frappier - 531 boul. des Prairies, Laval, QC H7V 1B7 (Canada)

${ }^{\text {d} U n i v e r s i t e ́ ~ d e ~ l ' i ̂ l e ~ d e ~ l a ~ R e ́ u n i o n ~-~ S t e m c i s ~ c / o ~ C Y R O I ~-~ 2, ~ r u e ~ m a x i m e ~ r i v i e ̀ r e, ~} 97490$ Sainte Clotilde (France)

\begin{abstract}
Neuroblastoma (NB) is a pediatric cancer. High-risk NB are characterized by poor differentiation, amplification of $M Y C N$ and mutations of $A L K$. Therapies are developed to induce cell differentiation and to inhibit MYCN and ALK signaling in NB. The vasoactive intestinal peptide (VIP) and the pituitary adenylate cyclase-activating polypeptide (PACAP) are 2 related neuropeptides sharing common receptors. VIP levels increase with NB differentiation. Here, the effects of VIP and PACAP analogs developed for therapeutic use were studied in $M Y C N$-amplified SK-N-DZ and IMR-32 cells and in Kelly cells that in addition present the F1174L $A L K$ mutation. As we previously observed for IMR-32 cells, VIP induced neuritogenesis in SK-N-DZ and Kelly cells, and it reduced MYCN expression in Kelly cells but not in SK-N-DZ cells. In parallel to its effect on MYCN expression, VIP decreased invasion in IMR-32 and Kelly cells. It also reduced AKT activity in the ALKmutated Kelly cells. Among the five PACAP analogs tested, [Hyp ${ }^{2}$ PACAP-27 showed higher efficiency than VIP in Kelly cells. These results indicate that VIP and PACAP analogs act on molecular and cellular processes that could reduce aggressiveness of high-risk NB.
\end{abstract}


Keywords: MYCN, ALK, AKT, PKA, invasion, differentiation

\section{Introduction}

Neuroblastoma (NB) is an embryonic tumor derived from the neural crest cells. It is the most common solid tumor in infants and children, and it accounts for approximately $15 \%$ of deaths due to pediatric tumors [1,2]. NB is characterized by a large clinical heterogeneity. Indeed, these tumors may regress completely or differentiate into a benign ganglioneuroblastoma without treatment while metastatic NB in children older than 18 months at diagnosis are lethal for most patients despite aggressive multimodal therapy [3].

Several critical genetic aberrations, such as deletions $1 p, 3 p$ and $11 q$ or gains $1 q, 2 p$ and $17 \mathrm{q}$, are identified in NB but only few established molecular markers are associated with outcome. The most important is the amplification of the $M Y C N$ locus that is found in about $25 \%$ of NB, and is strongly related to poor clinical outcome [1,2]. The involvement of $M Y C N$ in NB tumorigenesis was demonstrated in transgenic mice overexpressing $M Y C N$ in neural crest cells [4]. High expression of the transcription factor MYCN disrupts the cell-cycle exit and terminal differentiation that occurs during normal neuroblast development [5,6]. MYCN also plays an important role in cell invasion by directly or indirectly modulating specific target genes involved in cell adhesion, motility and matrix degradation [7].

Another oncogene found in NB is the anaplastic lymphoma kinase $(A L K)$. This tyrosine kinase receptor collaborates with MYCN for the development of most aggressive NB [8]. The F1174L $A L K$ mutation is associated preferentially with $M Y C N$ amplification in NB and induces constitutive activation of the PI3K/AKT pathway $[9,10]$. This constitutive activation leads to oncogenic stabilization of MYCN protein [11]. Poorly differentiated NB with high expression of MYCN and the F1174L $A L K$ mutation define a subset of patients with high-risk NB $[9,12]$.

Treating patients with high-risk NB is a challenge because about one-third of these patients do not respond completely to induction therapy $[13,14]$. New therapies inducing differentiation of NB cells and inhibiting specific signaling pathways, angiogenesis and ALK and MYCN expression are in development $[7,15,16]$.

The vasoactive intestinal peptide (VIP) and the pituitary adenylate cyclase-activating polypeptide (PACAP) are 2 related neuropeptides that share common receptors, named VPAC1 and VPAC2 [17]. These two receptors bind VIP and PACAP equally and activate mainly the protein kinase A (PKA) and protein kinase $\mathrm{C}(\mathrm{PKC})$ signaling pathways, which 
induce regulation of gene expression [18]. VIP and PACAP are involved in the development of the nervous system. VIP regulates the proliferation and the differentiation of neuronal precursors in vitro and in vivo, and is involved in the growth, differentiation and maintenance of neurons [19-21]. VIP can also regulate proliferation, differentiation and migration of various tumor cells [21,22]. In NB cell lines, this neuropeptide induces both inhibition of growth and morphological differentiation [23]. The rate of VIP increases with the degree of differentiation of NB and is associated with a good prognosis [24-26]. Our group demonstrated that VIP induces morphologic differentiation (neuritogenesis) and reduces $M Y C N$ expression in the high-risk NB IMR-32 cells with $M Y C N$ amplification [27]. Then VIP can regulate several processes that are the targets of new therapeutic strategies for high-risk NB. VIP can also up- or down-regulate invasion of different cancer cells depending of their tissue of origin [28-32]. However, its effect on NB cell invasion is unknown.

In the present study, we analyzed the effect of VIP on different molecular and cellular processes, i.e. neuritogenesis, $M Y C N$ expression, AKT activity and cell invasion, in high-risk NB cell lines with $M Y C N$ amplification, one also presenting the F1174L ALK mutation. Furthermore, the activity of stable peptidic analogs of PACAP developed for therapeutic use [33-35], was tested.

\section{Materials and methods}

\section{Cell culture}

Kelly and IMR-32 NB MYCN-amplified cells were routinely seeded at a density of $10^{6}$ cells $/ 25 \mathrm{~cm}^{2}$ flask in RPMI 1640 medium or DMEM medium $4.5 \mathrm{~g} / \mathrm{L}$ glucose, respectively, with GlutaMAX ${ }^{\mathrm{TM}}$ (Gibco) supplemented with 10\% fetal calf serum (FCS) and $100 \mathrm{U} / \mathrm{ml}$ penicillin and $100 \mu \mathrm{g} / \mathrm{ml}$ streptomycin (Invitrogen). These cells were incubated at $37^{\circ} \mathrm{C}$ in a humidified atmosphere of $5 \% \mathrm{CO}_{2}$ in air. SK-N-DZ cells were routinely seeded at a density of $10^{6}$ cells $/ 25 \mathrm{~cm}^{2}$ flask in DMEM medium with GlutaMAX supplemented with $10 \%$ fetal calf serum (FCS) and 1\% non essential amino acids (Sigma). SK-N-DZ cells were incubated at $37^{\circ} \mathrm{C}$ in a humidified atmosphere of $10 \% \mathrm{CO}_{2}$ in air. For all cell lines, medium was changed every 3 days. Passages were performed once per week using 1X Trypsin/EDTA (Invitrogen). 


\section{Peptides}

The VIP, PACAP-38, PACAP-27 and Secretin were from Neosystem (Strasbourg, France) while analogs were synthesis as previously described. Neuropeptides and analogs were diluted to a concentration of $10^{-4} \mathrm{M}$ in pure water or DMEM.

\section{Treatments}

Kelly, IMR-32 cells were seeded at a density of $2 \times 10^{6}$ and SK-N-DZ cells at $0.5 \times 10^{6}$ cells $/ 25$ $\mathrm{cm}^{2}$ flask in the media mentioned above except that they were supplemented with $5 \%$ FCS. After 2-3 days in culture, cells were treated with the neuropeptide VIP at a concentration of $10^{-6} \mathrm{M}$. An equal volume of phosphate buffered saline (PBS) was added to control cells. Treatments with secretin were performed at the concentration of $10^{-6} \mathrm{M}$, and those with PACAP-38, PACAP-27 and PACAP analogs at $10^{-7} \mathrm{M}$. For experiments in the presence of signaling pathway inhibitors, H-89 Dihydrochloride (Calbiochem) and AI (Akt Inhibitor VIII, Isozyme-Selective) were added 20 minutes before the addition of VIP, at a concentration of 1 and $10 \mu \mathrm{M}$.

\section{Micrographs of cells}

Video images of cells were captured using a digital camera connected to a phase-contrast Olympus microscope. The quantification of the number of cells with neurites and the measure of neurite length were performed using ImageJ software.

\section{Western immunoblot analysis}

After treatment, cells were recovered with versene, and cold PBS was added. Cells were centrifuged at $200 \mathrm{~g}$ for $10 \mathrm{~min}$ and the cell pellet was lysed with $10 \mu 1$ per $10^{6}$ cells of icecold lysis buffer [10m M Tris, pH 7.5, 0.5 mM EDTA, pH 8.0, 0.5\% CHAPS, 10\% glycerol] containing a cocktail of protease inhibitors diluted at $1 / 200^{\mathrm{e}}$ (Sigma-Aldrich). After $30 \mathrm{~min}$ on ice, the samples were centrifuged at $4^{\circ} \mathrm{C}$ for $20 \mathrm{~min}$ at $13000 \mathrm{~g}$. The supernatants were stored at $-80^{\circ} \mathrm{C}$. Protein concentration was determined by using the Bio-Rad DC Protein Assay (BioRad). Twenty $\mu \mathrm{g}$ of total proteins were electrophoresed in 10\% SDS-PAGE and electroblotted onto Immobilon-P membranes (Millipore). Membranes were blocked overnight at $4^{\circ} \mathrm{C}$ by 
using 5\% milk in TBS 0.1\%- Tween 20 (TSB-T) and incubated for $1 \mathrm{~h}$ at room temperature with anti-MYCN NCM II 100 antibodies (1:100; Calbiochem) or anti-GAPDH (1:160,000; ABCAM) or anti-Phospho AKT (1:1000; Cell Signaling Technology) or anti-PAN AKT (1:1000; Cell Signaling Technology) diluted in blocking solution. The membranes were rinsed 3x10 min at room temperature in TBS-T and incubated for $1 \mathrm{~h}$ with the secondary antibody anti-mouse IgG, H\&L Chain Specific (goat) peroxidase conjugated (1:20,000) (Calbiochem) in blocking solution. After three washes of 10 minutes at room temperature with TBS-T, and a supplementary rinse with TBS, the revelation of the antibodies bound to membranes was performed by using the chemiluminescence detection system "ECL Plus Western Blotting Detection System" (GE Healthcare). The blots were photographed and quantified using the software ImageJ.

\section{cDNA synthesis}

Total RNA was isolated by using the GenElute ${ }^{\mathrm{TM}}$ Mammalian Total RNA kit (Sigma-Aldrich) following the manufacturer's instructions. Total RNA was quantified with a GeneQuant II spectrophotometer (Pharmacia). Aliquots of total RNA were treated with $1 \mathrm{U} / \mu \mathrm{g}$ RNA of DNase I Amplification Grade (Invitrogen) according to the manufacturer's instructions, and in the presence of $10 \mathrm{U} / \mu \mathrm{g}$ RNA of RNaseOUT (Invitrogen). After DNase inactivation, RNA was reverse transcribed using random primers (Sigma- Aldrich) and $200 \mathrm{U} / \mu \mathrm{L}$ of M-MLV Reverse Transcriptase H Minus (Promega) according to the manufacturer's instruction.

\section{Real-time RT-PCR and quantification}

The protocol of RT-qPCR was carried out with the LightCycler System (Roche Molecular Biochemicals) by using the «SYBR Premix Ex Taq kit» (Takara) as previously described [36]. GAPDH mRNA levels were used to normalize the mRNA levels between samples. MYCN primers used were as followed: (5'-3') MYCN forward: CGACCACAAGGCCCTCAGT, MYCN reverse: TGACCACGTCGATTTCTTCCT. GAPDH primers used were as followed: (5'-3') GAPDH forward: GAAGGTGAAGGTCGGAGTCA, GAPDH reverse: GACAAGCTTCCCGTTCTCAG. The cycle program was: $5 \mathrm{sec}$ at $95^{\circ} \mathrm{C}, 5 \mathrm{sec}$ at $60^{\circ} \mathrm{C}$ and $10 \mathrm{sec}$ at $72^{\circ} \mathrm{C}$. 
Invasion

Invasion assays were carried out by using 24-well culture plates (BD Biosciences) using Transwell polycarbonate membrane filter inserts $(8-\mu \mathrm{m}$ pore size, BD Biosciences) coated with Matrigel (BD Biosciences) diluted at 1/80. Cells were collected using Versene solution. After centrifugation, cells were resuspended in medium containing 5\% FBS, incubated for 30 minutes at $4{ }^{\circ} \mathrm{C}$ with either PBS, VIP, Secretin or stable analogs under mild agitation and then placed in the inserts at a concentration of $10^{5}$ cells in $200 \mu 1$. In the lower compartment of the chambers, $700 \mu \mathrm{l}$ of the medium used for resuspension and containing or not the treatment were added. The plate was incubated at $37^{\circ} \mathrm{C}$ in a $\mathrm{CO}_{2}$ incubator. After $24 \mathrm{~h}$, the non-invading cells on the upper surface of the filters were removed with a cotton swab. The invading cells on the lower surface of the filters were fixed with cold methanol, stained with cresyl violet and counted using a phase-contrast Olympus microscope.

\section{Viability}

Cells were suspended and treated as described above for cell invasion assay. A volume of 100 $\mu 1$ of treatment medium containing 100,000 Kelly and IMR-32 cells was plated in 96-well plates coated with Matrigel, at the dose used to coat filters in the cell invasion assay. Cell viability was determined after $24 \mathrm{~h}$ in culture by adding $20 \mu \mathrm{l}$ of CellTiter $96^{\circledR}$ AQueous One Solution Reagent (Promega) per well, $3 \mathrm{~h}$ before measuring the optical densities in a microplate reader at $490 \mu \mathrm{m}$.

\section{Statistical analyses}

Statistical analyses were performed using the software GraphPad Prism.

\section{Results}

\section{I- VIP induces neuritogenesis in neuroblastoma cells}

VIP is able to induce neurite outgrowth in the $M Y C N$-amplified IMR-32 cell line $[27,37,38]$. In order to determine whether this differentiation process was found in other cell lines with $M Y C N$ amplification, Kelly and SK-N-DZ cells were treated with VIP $\left(10^{-6} \mathrm{M}\right)$. After treatment, Kelly and SK-N-DZ cell lines developed neurites (Figure 1 A-B). VIP induced a more important neuritogenesis in SK-N-DZ cells than in Kelly cells. This 
neuritogenesis was quantified according to the number of cells with neurites and the neurite length. In Kelly and SK-N-DZ cells, the percentage of cells with neurites increased from $1 \mathrm{~h}$ of treatment with VIP. This increase was almost doubled compared to control and remained stable for at least $6 \mathrm{~h}$ (Figure 1B and 1E). The neurite length increased with treatment time (Figure 1C and 1F). Indeed, while the length of neurites in control cells was broadly unchanged after 1 and $6 \mathrm{~h}$ of culture with a maximum of 11-20 $\mu \mathrm{m}$, those of Kelly cells treated with VIP extended from 1 to $140 \mu \mathrm{m}$ with a maximum of $11-20 \mu \mathrm{m}$ at $1 \mathrm{~h}$ and from 1 to $150 \mu \mathrm{m}$ with a maximum of $21-30 \mu \mathrm{m}$ at $6 \mathrm{~h}$; and those of SK-N-DZ cells treated with VIP was 50 to $450 \mu \mathrm{m}$ with a maximum of $150-200 \mu \mathrm{m}$ at $1 \mathrm{~h}$ and 50 to $700 \mu \mathrm{m}$ with a maximum of 300-350 $\mu \mathrm{m}$ at $6 \mathrm{~h}$. Thus, VIP induces neuritogenesis in $M Y C N$-amplified SK-N-DZ and Kelly cells as previously found in the $M Y C N$-amplified IMR-32 cells.

\section{II- VIP decreases MYCN expression in Kelly cells}

We previously observed that VIP decreased the expression of $M Y C N$ at the mRNA and protein levels in IMR-32 cell line [27]. Here, the effect of VIP on MYCN expression was analyzed in Kelly and SK-N-DZ cell lines. In SK-N-DZ cells, VIP did not change MYCN protein expression (Figure 2A). On the contrary, in Kelly cells, VIP induced a decrease in MYCN protein expression of 45, 40, 37 and 34\% compared to control, after 3, 6, 24 and $48 \mathrm{~h}$, respectively. After $72 \mathrm{~h}$ of treatment, VIP had no more effect on MYCN protein level (Figure $2 \mathrm{~B})$. The induced decrease was dose-dependent as determined using $10^{-8}$ to $10^{-6} \mathrm{M}$ VIP concentrations and specific to this neuropeptide since secretin, a peptide of the VIP family that does not bind VIP receptors, had no effect on MYCN expression (Figure $2 \mathrm{C}$ ). Thus, VIP induces a sustainable decrease in MYCN protein expression lasting at least for 2 days after addition of VIP to the culture medium in Kelly cells.

Quantitative RT-PCR analysis indicated that VIP reduced MYCN mRNA expression in Kelly cells by 31,47 and $48 \%$ after 1, 3 and 6 h of treatment, respectively, an effect no longer observable after $24 \mathrm{~h}$ of treatment (Figure 2D). Therefore, in Kelly cells, the decrease of MYCN expression induced by VIP is the result of a transcriptional or post-transcriptional regulation lasting few hours complemented by a translational or post-translational regulation leading to a sustainable effect over 2 days.

\section{III- The effect of VIP on MYCN expression and on neuritogenesis is PKA- dependent in Kelly and IMR-32 cells}


VIP often triggers a signaling pathway involving the activation of protein kinase A (PKA) [18]. To determine whether the regulation of MYCN expression and neuritogenesis by VIP involves PKA, Kelly and IMR-32 cells were pre-incubated with the PKA inhibitor H-89 before treatment with VIP (Figure 3). In both cell lines, H-89 at $10 \mu \mathrm{M}$ totally inhibited the VIP-induced decrease in MYCN expression (Figure $3 \mathrm{~A}-\mathrm{B}$ ). The VIP-induced neuritogenesis was also completely inhibited in IMR-32 cells in the presence of H-89 $(10 \mu \mathrm{M})$ and was reduced by about 2 thirds in Kelly cells (Figure 3C-D). Therefore, VIP regulates MYCN expression and neuritogenesis mainly via PKA in Kelly and IMR-32 cells.

\section{IV- VIP inhibits Kelly and IMR-32 cell invasion}

MYCN plays an important role in NB invasion [7]. To determine whether VIP can also acts on MYCN-amplified NB cell invasion, invasiveness of Kelly and IMR-32 cells treated with VIP was evaluated in transwell chamber coated with Matrigel (Figure 4 A-B). Under the same experimental conditions of Matrigel, Kelly cells were about 8.7 fold more invasive than IMR-32 cells. VIP inhibited invasion of Kelly cells by about 52\% and IMR-32 cells by about $61 \%$. This decrease in invasiveness was not due to changes in cell viability, as indicated by viability tests performed in the same conditions of treatment and Matrigel than those used in the invasion assays (Figure 4 C-D). Thus, as expected, the reduction of MYCN expression by VIP is associated with an inhibition of cell invasion in MYCN-amplified Kelly and IMR-32 cells.

\section{V- VIP-induced inhibition of AKT activity is PKA-dependent}

The PI3K/AKT signaling pathway is known to stabilize MYCN protein [16]. Kelly cells present the F1174L $A L K$ mutation that induces the constitutive activation of AKT, among others. We verified that AKT stabilizes MYCN protein in Kelly cells. In the presence of the AKT inhibitor (AI) at $10 \mu \mathrm{M}$ for $6 \mathrm{~h}, \mathrm{MYCN}$ protein decreased (Figure 5A) confirming that AKT stabilizes MYCN protein in these cells. We next wondered whether VIP acts on AKT activity. Phosphorylation of AKT at serine 473 is necessary for its kinase activity [39]. The data indicated that VIP decreased phosphorylation at serine 473 (P-AKT) after 3 and $6 \mathrm{~h}$ of treatment with VIP, in correlation with reduced MYCN expression. This reduction of P-AKT by VIP was PKA-dependent, as demonstrated when Kelly cells were pre-incubated with H-89 and next treated with VIP for $6 \mathrm{~h}$ (Figure 5C). Indeed, in presence of H-89 at $10 \mu \mathrm{M}$, VIP had 
no effect on P-AKT, indicating that VIP inhibits AKT activity via PKA, in parallel to its reduction in MYCN expression.

\section{VI- Effects of PACAP analogs on AKT activity}

VIP activity is mediated by the two receptors VPAC1 and VPAC2 that also bind the related peptide PACAP with equal affinity. PACAP is also the specific ligand of the receptor PAC1 [17]. Both VIP and PACAP are sensitive to peptidases, which limits their usefulness in therapy. Recently, some PACAP analogs with higher stability i.e. Acetyl-PACAP27proylamide and $\mathrm{N}$-Acetyl[$\left[\mathrm{Ala}^{15}, \mathrm{Ala}^{20}\right]$-PACAP38-propylamide (33) and/or increased specificity for the PAC1/VPAC1 receptors compared to the VPAC2 i.e. [Ala]PACAP27 and [Hyp $\left.{ }^{2}\right]$ PACAP27 (35) were developed for therapy of neuronal diseases (34). Here, the ability of those analogs to inhibit AKT activity in Kelly cells was compared to the one of native VIP and PACAP (Figure 6). Peptides were used at $10^{-7} \mathrm{M}$ due to the limited quantity available of the analogs. At this concentration, VIP, PACAP38 and PACAP27 reduced P-AKT for few hours with a maximum at $6 \mathrm{~h}$ for the three peptides. Stable analogs could also induce a rapid inhibition of P-AKT with a maximum effect after 1 hour of treatment. But more impressively, the 2 analogs with increased specificity for the PAC1/VPAC1 receptors triggered a faster (from $0.5 \mathrm{~h}$ ) and a more important decrease (maximum 99\%) VIP and PACAP. This effect of $\left[\mathrm{Ala}^{7}\right]$ PACAP-27 and $\left[\mathrm{Hyp}^{2}\right]$ PACAP-27 persisted for at least 6 hours.

\section{VII- Effects of $\left[\mathrm{Ala}^{7}\right]$ PACAP-27 and $\left[\mathrm{Hyp}^{2}\right]$ PACAP-27 on neuritogenesis, MYCN expression and cell invasion}

The effects of $\left[\mathrm{Ala}^{7}\right]$ PACAP-27 and $\left[\mathrm{Hyp}^{2}\right]$ PACAP-27 analogs were then further tested on neuritogenesis, MYCN expression and invasion in Kelly cells. Both analogs at $10^{-7} \mathrm{M}$ increased the percentage of cells with neurites more than VIP at the same concentration and often even more than VIP at $10^{-6} \mathrm{M}$ (Figure $7 \mathrm{~A}-\mathrm{D}$ ). Furthermore, the effects of $\left[\mathrm{Ala}^{7}\right]$ PACAP-27 and $\left[\mathrm{Hyp}^{2}\right]$ PACAP-27 lasted more than the effect of VIP as the neuritogenesis they induced was still statistically significant after $24 \mathrm{~h}$ of treatment, contrary to VIP (Figure 7D). [Hyp ${ }^{2}$ PACAP-27 had a better efficiency to reduce MYCN expression than [Ala ${ }^{7}$ PACAP-27 (Figure $7 \mathrm{E}$ and F). This decrease was faster and more important (88\%) than the effect observed with VIP $10^{-6} \mathrm{M}$ (Figure $2 \mathrm{~B}$ ). Kelly cell invasion was inhibited by $\left[\mathrm{Hyp}^{2}\right]$ PACAP-27 but not by $\left[\mathrm{Ala}^{7}\right]$ PACAP-27 or VIP at $10^{-7} \mathrm{M}$ (Figure $7 \mathrm{G}$ ). This was close 
to the effect obtained with VIP at $10^{-6} \mathrm{M}$ and not due to changes in viability in the presence of Matrigel (Figure $7 \mathrm{H}$ ). Thus the analog $\left[\mathrm{Hyp}^{2}\right]$ PACAP-27, in addition to its better effect than VIP on AKT activity, presents also a more important and more sustainable activity on neuritogenesis and is more efficient than VIP to decrease MYCN expression and Kelly cell invasion. At a 10 fold lower concentration, [Hyp ${ }^{2}$ PACAP-27 has a better or similar efficiency than VIP.

\section{Discussion}

New therapies are needed to improve the treatment of patients with high-risk NB. Knowledge of the molecular and cellular characteristics of these high-risk NB allows to consider the development of treatments able to induce NB differentiation and inhibition of signaling pathways, angiogenesis and the expression of the oncogenes $A L K$ and MYCN [7]. The transcription factor MYCN regulates many processes in NB cells, notably differentiation, metastasis, angiogenesis and then constitutes a major therapeutic target. This therapeutic relevance was demonstrated in a mouse model of NB that overexpresses MYCN in cells derived from neural crest. In these mice, the administration of antisense oligonucleotides inhibiting $M Y C N$ expression reduces the tumor incidence and tumor mass [40]. Here, we report that the neuropeptide VIP and analogs of the related peptide PACAP targeting PAC1 and VPAC1 receptors regulate differentiation, MYCN expression, AKT activity and invasion in $M Y C N$-amplified NB cells.

The data from the present study and from a previous one of our group demonstrated that VIP induces a differentiation, i.e. neuritogenesis, in the $M Y C N$-amplified NB cell lines, Kelly, IMR-32 and SK-N-DZ, and decreases MYCN expression in Kelly and IMR-32 cells but not in SK-N-DZ cells. Several studies indicated that MYCN and neuritogenesis are related. Indeed, experiments demonstrated that a knockdown of MYCN expression using antisense oligonucleotides or RNA interference in MYCN-amplified NB cells induces an increase in apoptosis and differentiation, and a suppression of cell growth [7,40-42]. In agreement with this, we found that MYCN expression and differentiation are inversely correlated in Kelly and IMR-32 MYCN-amplified cell lines. However, a decrease in MYCN expression is not necessary to obtain important neuritogenesis in SK-N-DZ MYCN-amplified cells showing the cell-context dependence of the VIP-induced differentiation. 
Metastases are the main cause of death of NB patients [43]. MYCN plays an important role in NB invasion. Indeed, this transcriptional factor directly or indirectly can down-regulate integrin expression, up-regulate transcription of focal adhesion kinase (FAK), induce MMP activity and inhibit E-cadherin expression [7]. These modulations increase migration and invasion of NB cells. Here, we report that VIP reduces in vitro invasion in both Kelly and IMR-32 MYCN-amplified cells. In our experiments, Kelly cells were about 9-fold more invasive than IMR-32 cells. This is in agreement with the observation that invasion capacity of NB cells correlates with MYCN levels [7]. Indeed, Kelly and IMR-32 cells possess about 100-120 and 15 copies of MYCN per haploide genome, respectively [43,44]. The effect of VIP on invasion of these two cell lines was about $50-60 \%$, even in the highly invasive and highly $M Y C N$-amplified Kelly cells. This important effect in the more invasive Kelly cells could be due to the sustainable (2 days) decrease in MYCN expression induced by VIP, compared to the more transient (few hours) reduction of MYCN expression obtained in IMR-32 cells treated with VIP [27].

ALK is another therapeutic target considered for the treatment of NB [16]. Mutations of this receptor tyrosine kinase collaborate with $M Y C N$ in NB pathogenesis $[8,10]$. These mutations lead to constitutive activation of AKT signaling, a pathway known to inhibit MYCN proteasomal degradation [45]. In our study, the inhibition of AKT activity induced by VIP could be responsible for the post-translational down-regulation of MYCN expression observed in VIP-treated Kelly cells.

Numerous $A L K$ mutations have been identified in NB cells [9]. The $A L K$ mutations F1178L and R1279Q were recently shown to increase VIP expression in NB tumors from mice with one of these ALK mutations and overexpressing MYCN [46]. Whether the F1174L $A L K$ mutation could up-regulate VIP expression in Kelly cells is unknown, but if this happens, then the endogenous VIP is not produced enough to prevent exogenous VIP to act on these cells.

PKA is often involved in the signaling triggered by VIP [18]. Our data indicate that the effect of VIP on neuritogenesis and MYCN expression in Kelly and IMR-32 cells, as well as on AKT activity in Kelly cells, is PKA-dependent. Thus PKA plays an important role in VIP signaling in NB cells, as we observed in glioblastoma cells (Bensalma et al., manuscript in preparation) that also derived from the nervous system.

Peptidic analogs of PACAP that are more resistant to peptidases and more selective for certain receptors were designed for therapy [33-35]. In the high-risk NB Kelly cells, the most effective of the five analogs tested is $\left[\mathrm{Hyp}^{2}\right]$ PACAP-27. Indeed, this analog is more 
potent than VIP on neuritogenesis, MYCN expression, AKT activity and cell invasion. [Hyp $\left.{ }^{2}\right]$ PACAP-27 corresponds to PACAP-27 in which serine at position 2 is replaced by hydroxyproline. This modification confers selectivity for PAC1/VPAC1 receptors because of a lower activation of VPAC2 receptors, as determined in transfected $\mathrm{CHO}$ cells expressing the human PAC1, VPAC1 or VPAC2 [35,47]. This suggests that, in Kelly cells, the effect of VIP is mediated by the VPAC1 receptor which binds VIP and PACAP while PAC1 is a PACAPspecific receptor. However, further investigations are required to determine which receptor is involved, because VPAC1 mRNA is only weakly expressed in Kelly cells while VPAC2 mRNA is present in a large quantity (de Boisvilliers, unpublished data).

In the kinetic experiments with VIP and PACAP analogs (Figure 6), a biphasic effect on phospho-AKT is often observed with a decrease in P-AKT at 1-2 $\mathrm{h}$ and at $6 \mathrm{~h}$ but not at the intermediate time point $(3 \mathrm{~h})$. This could be due to receptor desensitization, down-regulation or internalization as already described for VIP and PACAP receptors $[48,49]$.

This study showed that VIP and PACAP analogs developed for therapy act on molecular and cellular processes that are of interest for treatment of high-risk NB. So far, small molecules directly inhibiting MYCN have not yet been found, thus non-small molecules and indirect inhibitors are sought for therapy [7,16]. Peptidic analogs able to induce a sustainable decrease in MYCN expression would be of interest not only for therapy of NB but also for other tumors such as neuroendocrine prostate cancer for which $40 \%$ present a MYCN amplification [50].

\section{Acknowledgements}

This work was supported by grants from the "Ligue contre le Cancer du Grand-Ouest, comité de la Vienne" and from the "Lions Club de Melle". Madryssa de Boisvilliers and Souheyla Bensalma were recipients of Ph.D. fellowships from the "Région Ile de la Réunion » and from the « Région Poitou-Charentes », respectively.

\section{References}

[1] G.M. Brodeur, Neuroblastoma: biological insights into a clinical enigma, Nat Rev Cancer. 3 (2003) 203-16. doi:10.1038/nrc1014.

[2] J.M. Maris, M.D. Hogarty, R. Bagatell, S.L. Cohn, Neuroblastoma, Lancet. 369 (2007) 2106-20. doi:10.1016/S0140-6736(07)60983-0.

[3] S. Modak, N.K. Cheung, Neuroblastoma: Therapeutic strategies for a clinical enigma, Cancer Treat Rev. 36 (2010) 307-17. doi:10.1016/j.ctrv.2010.02.006. 
[4] W.A. Weiss, K. Aldape, G. Mohapatra, B.G. Feuerstein, J.M. Bishop, Targeted expression of MYCN causes neuroblastoma in transgenic mice, EMBO J. 16 (1997) 2985-95. doi:10.1093/emboj/16.11.2985.

[5] M.R. Grimmer, W.A. Weiss, Childhood tumors of the nervous system as disorders of normal development, Curr. Opin. Pediatr. 18 (2006) 634-638. doi:10.1097/MOP.0b013e32801080fe.

[6] G.M. Marshall, D.R. Carter, B.B. Cheung, T. Liu, M.K. Mateos, J.G. Meyerowitz, et al., The prenatal origins of cancer, Nat. Rev. Cancer. 14 (2014) 277-289. doi: $10.1038 / \mathrm{nrc} 3679$.

[7] M. Huang, W.A. Weiss, Neuroblastoma and MYCN, Cold Spring Harb. Perspect. Med. 3 (2013) a014415. doi:10.1101/cshperspect.a014415.

[8] S. Zhu, J.S. Lee, F. Guo, J. Shin, A.R. Perez-Atayde, J.L. Kutok, et al., Activated ALK collaborates with MYCN in neuroblastoma pathogenesis, Cancer Cell. 21 (2012) 36273. doi:10.1016/j.ccr.2012.02.010.

[9] S. De Brouwer, K. De Preter, C. Kumps, P. Zabrocki, M. Porcu, E.M. Westerhout, et al., Meta-analysis of neuroblastomas reveals a skewed ALK mutation spectrum in tumors with MYCN amplification, Clin Cancer Res. 16 (2010) 4353-62. doi:10.1158/10780432.CCR-09-2660.

[10] T. Berry, W. Luther, N. Bhatnagar, Y. Jamin, E. Poon, T. Sanda, et al., The ALK(F1174L) mutation potentiates the oncogenic activity of MYCN in neuroblastoma, Cancer Cell. 22 (2012) 117-30. doi:10.1016/j.ccr.2012.06.001.

[11] L. Chesler, C. Schlieve, D.D. Goldenberg, A. Kenney, G. Kim, A. McMillan, et al., Inhibition of phosphatidylinositol 3-kinase destabilizes Mycn protein and blocks malignant progression in neuroblastoma, Cancer Res. 66 (2006) 8139-8146. doi:10.1158/0008-5472.CAN-05-2769.

[12] E. Fredlund, M. Ringnér, J.M. Maris, S. Påhlman, High Myc pathway activity and low stage of neuronal differentiation associate with poor outcome in neuroblastoma, Proc Natl Acad Sci U A. 105 (2008) 14094-9. doi:10.1073/pnas.0804455105.

[13] E.A. Shafford, D.W. Rogers, J. Pritchard, Advanced neuroblastoma: improved response rate using a multiagent regimen (OPEC) including sequential cisplatin and VM-26, J. Clin. Oncol. Off. J. Am. Soc. Clin. Oncol. 2 (1984) 742-747.

[14] V. Castel, V. Segura, P. Berlanga, Emerging drugs for neuroblastoma, Expert Opin. Emerg. Drugs. 18 (2013) 155-171. doi:10.1517/14728214.2013.796927.

[15] U.K. Westermark, M. Wilhelm, A. Frenzel, M.A. Henriksson, The MYCN oncogene and differentiation in neuroblastoma, Semin Cancer Biol. 21 (2011) 256-66. doi:10.1016/j.semcancer.2011.08.001.

[16] G. Barone, J. Anderson, A.D.J. Pearson, K. Petrie, L. Chesler, New strategies in neuroblastoma: Therapeutic targeting of MYCN and ALK, Clin. Cancer Res. Off. J. Am. Assoc. Cancer Res. 19 (2013) 5814-5821. doi:10.1158/1078-0432.CCR-13-0680.

[17] A.J. Harmar, J. Fahrenkrug, I. Gozes, M. Laburthe, V. May, J.R. Pisegna, et al., Pharmacology and functions of receptors for vasoactive intestinal peptide and pituitary adenylate cyclase-activating polypeptide: IUPHAR review 1, Br J Pharmacol. 166 (2012) 4-17. doi:10.1111/j.1476-5381.2012.01871.x.

[18] L. Dickson, K. Finlayson, VPAC and PAC receptors: From ligands to function, Pharmacol Ther. 121 (2009) 294-316. doi:10.1016/j.pharmthera.2008.11.006.

[19] I. Gozes, D.E. Brenneman, Neuropeptides as growth and differentiation factors in general and VIP in particular, J Mol Neurosci. 4 (1993) 1-9. doi:10.1007/BF02736685.

[20] P. Gressens, J.M. Hill, I. Gozes, M. Fridkin, D.E. Brenneman, Growth factor function of vasoactive intestinal peptide in whole cultured mouse embryos, Nature. 362 (1993) 1558. doi:10.1038/362155a0. 
[21] J.M. Muller, V. Lelievre, L. Becq-Giraudon, A.C. Meunier, VIP as a cell-growth and differentiation neuromodulator role in neurodevelopment, Mol Neurobiol. 10 (1995) 115-34. doi:10.1007/BF02740671.

[22] T.W. Moody, D. Chan, J. Fahrenkrug, R.T. Jensen, Neuropeptides as autocrine growth factors in cancer cells, Curr Pharm Des. 9 (2003) 495-509.

[23] J.M. Muller, M. Philippe, L. Chevrier, C. Héraud, C. Alleaume, C. Chadéneau, The VIPreceptor system in neuroblastoma cells, Regul Pept. 137 (2006) 34-41. doi:10.1016/j.regpep.2006.06.014.

[24] S.J. Qualman, M.S. O’Dorisio, D.J. Fleshman, H. Shimada, T.M. O’Dorisio, Neuroblastoma. Correlation of neuropeptide expression in tumor tissue with other prognostic factors, Cancer. 70 (1992) 2005-2012.

[25] M.C. Frühwald, M.S. O’Dorisio, S.L. Cottingham, S.J. Qualman, T.M. O’Dorisio, Neuropeptides in developmental tumors of the central and peripheral nervous system, Ann. N. Y. Acad. Sci. 865 (1998) 420-426.

[26] J.L. Grosfeld, Risk-based management of solid tumors in children, Am J Surg. 180 (2000) 322-7.

[27] L. Chevrier, A.-C. Meunier, S. Cochaud, J.-M. Muller, C. Chadéneau, Vasoactive intestinal peptide decreases MYCN expression and synergizes with retinoic acid in a human MYCN-amplified neuroblastoma cell line, Int. J. Oncol. 33 (2008) 1081-1089.

[28] A.B. Fernández-Martínez, A.M. Bajo, M. Isabel Arenas, M. Sánchez-Chapado, J.C. Prieto, M.J. Carmena, Vasoactive intestinal peptide (VIP) induces malignant transformation of the human prostate epithelial cell line RWPE-1, Cancer Lett. 299 (2010) 11-21. doi:10.1016/j.canlet.2010.07.019.

[29] M. Ogasawara, J. Murata, K. Ayukawa, I. Saiki, Differential effect of intestinal neuropeptides on invasion and migration of colon carcinoma cells in vitro, Cancer Lett. 119 (1997) 125-30.

[30] A.B. Fernández-Martínez, A.M. Bajo, M. Sánchez-Chapado, J.C. Prieto, M.J. Carmena, Vasoactive intestinal peptide behaves as a pro-metastatic factor in human prostate cancer cells, The Prostate. 69 (2009) 774-786. doi:10.1002/pros.20930.

[31] E. Vacas, M.I. Arenas, L. Muñoz-Moreno, A.M. Bajo, M. Sánchez-Chapado, J.C. Prieto, et al., Antitumoral effects of vasoactive intestinal peptide in human renal cell carcinoma xenografts in athymic nude mice, Cancer Lett. 336 (2013) 196-203. doi:10.1016/j.canlet.2013.04.033.

[32] S. Cochaud, A.-C. Meunier, A. Monvoisin, S. Bensalma, J.-M. Muller, C. Chadéneau, Neuropeptides of the VIP family inhibit glioblastoma cell invasion, J. Neurooncol. 122 (2015) 63-73. doi:10.1007/s11060-014-1697-6.

[33] S. Bourgault, D. Vaudry, B. Botia, A. Couvineau, M. Laburthe, H. Vaudry, et al., Novel stable PACAP analogs with potent activity towards the PAC1 receptor, Peptides. 29 (2008) 919-932. doi:10.1016/j.peptides.2008.01.022.

[34] A. Dejda, T. Seaborn, S. Bourgault, O. Touzani, A. Fournier, H. Vaudry, et al., PACAP and a novel stable analog protect rat brain from ischemia: Insight into the mechanisms of action, Peptides. 32 (2011) 1207-1216. doi:10.1016/j.peptides.2011.04.003.

[35] N.-D. Doan, S. Bourgault, A. Dejda, M. Létourneau, M. Detheux, D. Vaudry, et al., Design and in vitro characterization of PAC1/VPAC1-selective agonists with potent neuroprotective effects, Biochem. Pharmacol. 81 (2011) 552-561. doi:10.1016/j.bcp.2010.11.015.

[36] S. Bensalma, C. Chadeneau, T. Legigan, B. Renoux, A. Gaillard, M. de Boisvilliers, et al., Evaluation of cytotoxic properties of a cyclopamine glucuronide prodrug in rat glioblastoma cells and tumors, J. Mol. Neurosci. MN. 55 (2015) 51-61. doi:10.1007/s12031-014-0395-3. 
[37] M.S. O’Dorisio, D.J. Fleshman, S.J. Qualman, T.M. O’Dorisio, Vasoactive intestinal peptide: autocrine growth factor in neuroblastoma, Regul. Pept. 37 (1992) 213-226.

[38] J.C. Pence, N.A. Shorter, In vitro differentiation of human neuroblastoma cells caused by vasoactive intestinal peptide, Cancer Res. 50 (1990) 5177-5183.

[39] M. Qiao, S. Sheng, A.B. Pardee, Metastasis and AKT activation, Cell Cycle Georget. Tex. 7 (2008) 2991-2996.

[40] C.A. Burkhart, A.J. Cheng, J. Madafiglio, M. Kavallaris, M. Mili, G.M. Marshall, et al., Effects of MYCN antisense oligonucleotide administration on tumorigenesis in a murine model of neuroblastoma, J Natl Cancer Inst. 95 (2003) 1394-403.

[41] J.-H. Kang, P.G. Rychahou, T.A. Ishola, J. Qiao, B.M. Evers, D.H. Chung, MYCN silencing induces differentiation and apoptosis in human neuroblastoma cells, Biochem. Biophys. Res. Commun. 351 (2006) 192-197. doi:10.1016/j.bbrc.2006.10.020.

[42] J.R. Henriksen, B.H. Haug, J. Buechner, E. Tømte, C. Løkke, T. Flaegstad, et al., Conditional expression of retrovirally delivered anti-MYCN shRNA as an in vitro model system to study neuronal differentiation in MYCN-amplified neuroblastoma, BMC Dev Biol. 11 (2011) 1. doi:10.1186/1471-213X-11-1.

[43] S. Fulda, M. Honer, I. Menke-Moellers, F. Berthold, Antiproliferative potential of cytostatic drugs on neuroblastoma cells in vitro, Eur J Cancer. 31A (1995) 616-21.

[44] Y. Zaizen, S. Taniguchi, S. Noguchi, S. Suita, The effect of N-myc amplification and expression on invasiveness of neuroblastoma cells, J. Pediatr. Surg. 28 (1993) 766-769.

[45] W.C. Gustafson, W.A. Weiss, Myc proteins as therapeutic targets, Oncogene. 29 (2010) 1249-59. doi:10.1038/onc.2009.512.

[46] A. Cazes, L. Lopez-Delisle, K. Tsarovina, C. Pierre-Eugène, K. De Preter, M. Peuchmaur, et al., Activated Alk triggers prolonged neurogenesis and Ret upregulation providing a therapeutic target in ALK-mutated neuroblastoma, Oncotarget. 5 (2014) 2688-2702.

[47] H. Igarashi, T. Ito, T.K. Pradhan, S.A. Mantey, W. Hou, D.H. Coy, et al., Elucidation of the vasoactive intestinal peptide pharmacophore for VPAC(2) receptors in human and rat and comparison to the pharmacophore for VPAC(1) receptors, J. Pharmacol. Exp. Ther. 303 (2002) 445-460. doi:10.1124/jpet.102.038075.

[48] J.-C. Marie, C. Rouyer-Fessard, A. Couvineau, P. Nicole, H. Devaud, J. El Benna, et al., Serine 447 in the carboxyl tail of human VPAC1 receptor is crucial for agonist-induced desensitization but not internalization of the receptor, Mol. Pharmacol. 64 (2003) 15651574. doi:10.1124/mol.64.6.1565.

[49] K.S. Murthy, S. Mahavadi, J. Huang, H. Zhou, W. Sriwai, Phosphorylation of GRK2 by PKA augments GRK2-mediated phosphorylation, internalization, and desensitization of VPAC2 receptors in smooth muscle, Am. J. Physiol. Cell Physiol. 294 (2008) C477487. doi:10.1152/ajpcell.00229.2007.

[50] H. Beltran, The N-myc Oncogene: Maximizing its Targets, Regulation, and Therapeutic Potential, Mol. Cancer Res. MCR. 12 (2014) 815-822. doi:10.1158/1541-7786.MCR13-0536.

\section{Figure Legends}

Figure 1: VIP induces neuritogenesis in SK-N-DZ and Kelly cells. A) Phase contrast micrographs of SK-N-DZ NB cells treated (VIP) or not (control) with VIP at $10^{-6} \mathrm{M}$. Cells 
developed neurites (indicated by white arrows) after treatment with VIP. Scale bar corresponds to $50 \mu \mathrm{m}$ and applies to all micrographs. B) Percentage of SK-N-DZ cells with neurites after culture in the presence (VIP) or absence (control) of VIP at different treatment times. The number of cells with neurites was determined for each condition on four phase contrast micrographs. C) Percentage of SK-N-DZ cells with neurites according to their length (in $\mu \mathrm{m}$ ) after a treatment with (VIP) or without (control) VIP at different time points. The data are from the analysis of two independent experiments. D) Phase contrast micrographs of Kelly cells treated (VIP) or not (control) with VIP $\left(10^{-6} \mathrm{M}\right)$. Cells developed neurites (indicated by white arrows) after treatment with VIP. E-F) Quantification of the effect of VIP on Kelly cell morphology. The techniques used for the analysis are as described in B and C. The data are from the analysis of two independent experiments.

Figure 2: VIP effect on MYCN expression in SK-N-DZ and Kelly cells. Kelly cells (A) and SK-N-DZ cells (B) were treated (V, VIP) or not (C, Control) with VIP $10^{-6} \mathrm{M}$ for the indicated times. Total proteins were extracted and analyzed by immunoblotting with antibodies to MYCN and GAPDH. GAPDH was used as loading control. Top panels correspond to a representative experiment and bottom panels present cumulative data from three independent experiments after quantification using densitometry. The histogram bars represent the mean \pm SEM. The statistical test used was the Wilcoxon test (** $\mathrm{P}<0.01, * * * \mathrm{P}<0.001)$. C) Total proteins were extracted from Kelly cells treated or $\operatorname{not}(\mathrm{C})$ with secretin $\left(10^{-6} \mathrm{M}\right)$ or with the indicated concentrations of VIP for $6 \mathrm{~h}$. The top panel corresponds to a representative experiment and the bottom panel present cumulative data from two independent experiments after quantification using densitometry. The histogram bars represent the mean \pm SEM from two independent experiments. The statistical test used was the Kruskal Wallis (** $\mathrm{P}<0.001)$. D) Expression of MYCN mRNA was analyzed by quantitative RT-PCR in Kelly cells treated (VIP) or not (Control) with VIP $\left(10^{-6} \mathrm{M}\right)$ at the indicated times. GAPDH mRNA was used to normalize the results. The histogram bars represent the mean \pm SEM from three independent experiments analyzed in quadruplicate. The statistical test used was the Mann Whitney test $(* * * \mathrm{P}<0.0001)$.

Figure 3: Effect of the PKA inhibitor H-89 on the regulation by VIP of MYCN protein expression and neuritogenesis in Kelly and IMR-32 cells. Kelly (A) and IMR-32 (B) cells 
underwent a 20-minute incubation without (NT) or with H-89 at a concentration of 1 and 10 $\mu \mathrm{M}$ followed by a treatment with (V, VIP) or without (C, Control) VIP for $6 \mathrm{~h}$ (Kelly) or $3 \mathrm{~h}$ (IMR-32). MYCN protein expression analysis and quantification were performed as described in Figure $2 \mathrm{~A}$ and B. Top panels correspond to a representative experiment and bottom panels present cumulative data from three independent experiments. The histogram bars represent the mean $\pm \mathrm{SEM}$. The statistical test used is the Wilcoxon test (** $\mathrm{P}<0.01, * * * \mathrm{P}<0.001)$. C and D) Cells were pre-incubated and treated as above, and the percentage of cells with neurites was quantified for Kelly (C) and IMR-32 (D) cells. Quantification was performed as described in Figure $1 \mathrm{C}$ and the data were from three independent experiments. The statistical test used is the Wilcoxon test for paired data $(* * \mathrm{P}<0.01$, *** $\mathrm{P}<0.001)$ and Mann Whitney test for impaired data $\left.{ }^{(\# \#} \mathrm{P}<0.01,{ }^{\# \#} \mathrm{P}<0.0001\right)$.

Figure 4: VIP inhibits Kelly and IMR-32 cell invasion. Kelly cells (A) or IMR-32 cells (B) were seeded onto filters pre-coated with Matrigel on the upper surface, in transwell chambers, and treated or not (Control) with VIP or secretin at $10^{-6} \mathrm{M}$. After $24 \mathrm{~h}$, the cells that migrated to the lower surface were fixed, stained with cresyl violet and counted. The histogram bars represent the mean \pm SEM from three (A) or two (B) independent experiments. The statistical test used was the Kruskal Wallis ( $* \mathrm{P}<0.05, * * \mathrm{P}<0.001)$. C and D) MTS assays were used to evaluate Kelly (C) and IMR-32 (D) cell viability on Matrigel. Values were obtained from two independent experiments analyzed in quadruplicates.

Figure 5: VIP decreases AKT activity in Kelly cells via PKA. Top panels correspond to a representative experiment and bottom panels present cumulative data from independent experiments after quantification using densitometry. The histogram bars represent the mean \pm SEM. A) Kelly cells underwent a 6-h incubation with the AKT inhibitor (AI) at a concentration of 1 and $10 \mu \mathrm{M}$ before protein extraction. MYCN expression was analyzed by immunoblotting as described in Figure 2. Values were obtained from two independent experiments. The statistical test used was the Kruskal Wallis (** $\mathrm{P}<0.001)$. B) Total proteins were extracted from Kelly cells treated with VIP $10^{-6} \mathrm{M}$ for the indicated times. AKT was analyzed by immunoblotting with antibodies to AKT phosphorylated at serine 473 (P-AKT) and antibodies to total AKT (AKT). GAPDH was used as loading control. Values were obtained from two independent experiments. The statistical test used was the Friedman test $(* \mathrm{P}<0,05) . \mathrm{C})$ Kelly cells underwent a 20 -minute incubation with $\mathrm{H}-89$ at a concentration of 1 and $10 \mu \mathrm{M}$ followed by a treatment with (VIP) or without (Control) VIP for $6 \mathrm{~h}$. Analysis 
was performed as in B. Values were obtained from three independent experiments. The statistical test used was the Wilcoxon test $(* \mathrm{P}<0.1, * * \mathrm{P}<0.01)$.

Figure 6: Effects of PACAP analogs on AKT activity in Kelly cells. Cells were treated with VIP, PACAP-38, PACAP-27 and PACAP analogs at $10^{-7} \mathrm{M}$ for the indicated times. AKT analysis was performed as described in Figure $5 \mathrm{~B}$. Top panels correspond to a representative experiment and bottom panels present cumulative data after quantification using densitometry. The histogram bars represent the mean \pm SEM. The data were expressed as mean \pm SEM from three independent experiments for VIP and PACAP-38, and from two independent experiments for analogs. The statistical test used was the Friedman test $(* \mathrm{P}<$ $0.05, * * \mathrm{P}<0.01, * * * \mathrm{P}<0.001)$. Each treatment was compared to control $(\mathrm{t}=0 \mathrm{~h})$.

Figure 7: Effects of $\left[\mathrm{Ala}^{7}\right]$ PACAP-27 and $\left[\mathrm{Hyp}^{2}\right]$ PACAP-27 analogs on neuritogenesis, MYCN expression and invasion in Kelly cells. A) Cells were treated with VIP, $\left[\mathrm{Ala}^{7}\right]$ PACAP-27 or $\left[\mathrm{Hyp}^{2}\right]$ PACAP-27 and then micrographed after the indicated times. Cells developed neurites after treatments compared to control. Scale bar corresponds to $50 \mu \mathrm{m}$ and applies to all micrographs of the same row. B-D) Histogram of the percentage of cells with neurites after $1 \mathrm{~h}(\mathrm{~B}), 6 \mathrm{~h}$ (C) or $24 \mathrm{~h}$ (D) of treatment. The number of cells with neurites was determined as described in Figure 1B. The data are expressed as mean \pm SEM from two independent experiments. The statistical test used was the Kruskal Wallis test $\left({ }^{*} \mathrm{P}<0.05\right.$, **P $<0.01, * * * \mathrm{P}<0.001)$. $\mathrm{E}$ and $\mathrm{F})$ Total proteins were extracted from cells treated with [Ala $\left.{ }^{7}\right]$ PACAP-27 (E) or $\left[\mathrm{Hyp}^{2}\right]$ PACAP-27 (F) at $10^{-7} \mathrm{M}$ for the indicated times. Analysis of MYCN expression was as described in Figure 2 B. Top panels correspond to a representative experiment and bottom panels present cumulative data from two independent experiments after quantification using densitometry. The histogram bars represent the mean \pm SEM. The statistical test used was the Friedman test ( $* \mathrm{P}<0.05, * * \mathrm{P}<0.01, * * * \mathrm{P}<0.001)$. G) Cells were cultured on Matrigel as described in Figure $4 \mathrm{~A}$ and treated or not (control) with secretin, VIP, $\left[\mathrm{Ala}^{7}\right]$ PACAP-27 or $\left[\mathrm{Hyp}^{2}\right]$ PACAP-27 at the indicated concentrations. After 24 $\mathrm{h}$, invasive cells were counted as described in Figure $4 \mathrm{~A}$. The data are expressed as mean \pm SEM from four independent experiments. The statistical test used was the Kruskal Wallis test $(* \mathrm{P}<0.05, * * \mathrm{P}<0.01) . \mathrm{H})$ Kelly cell viability on Matrigel after treatments with the analogs was evaluated by MTS assays. Values were obtained from two independent experiments analyzed in quadruplicates. 

A
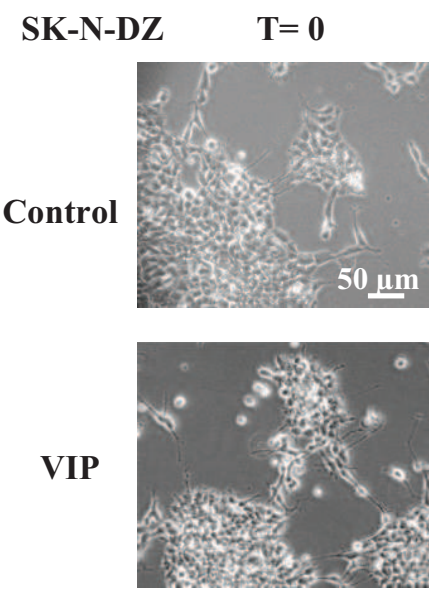

C

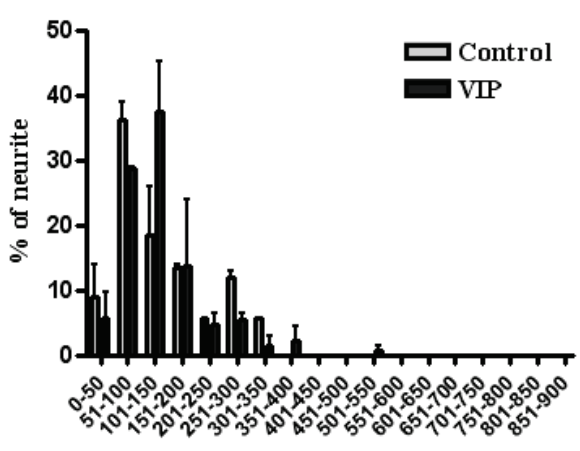

Length of neurite (in $\mu \mathrm{m}$ )
Figure 1
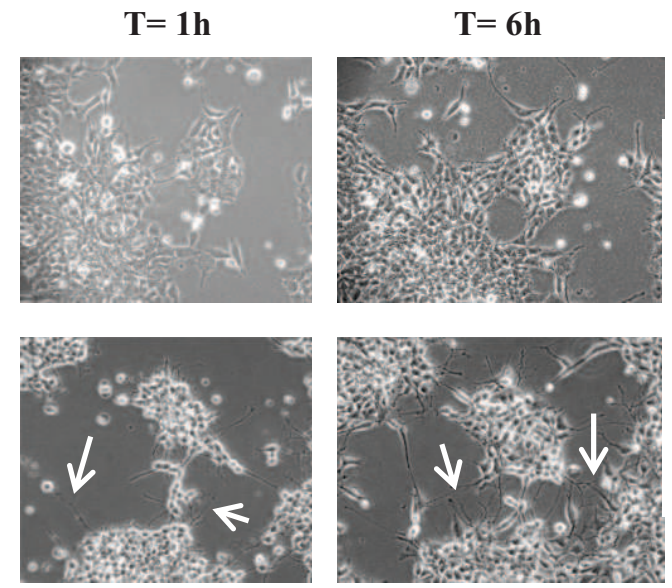

$T=1 h$

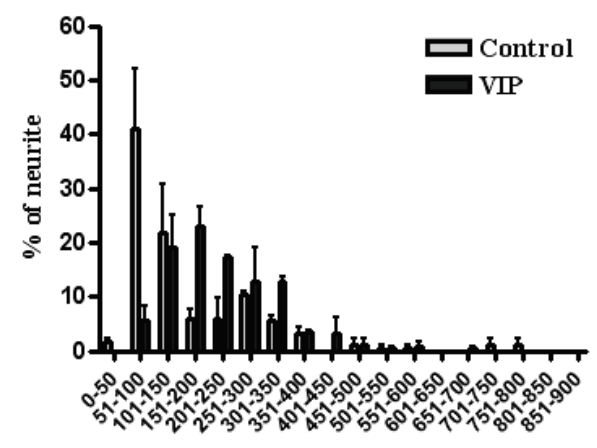

Length of neurite (in $\mu \mathrm{m}$ )

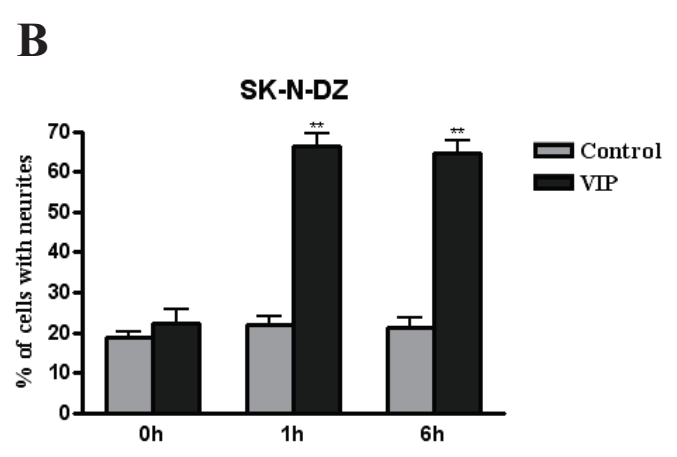

$T=6 h$

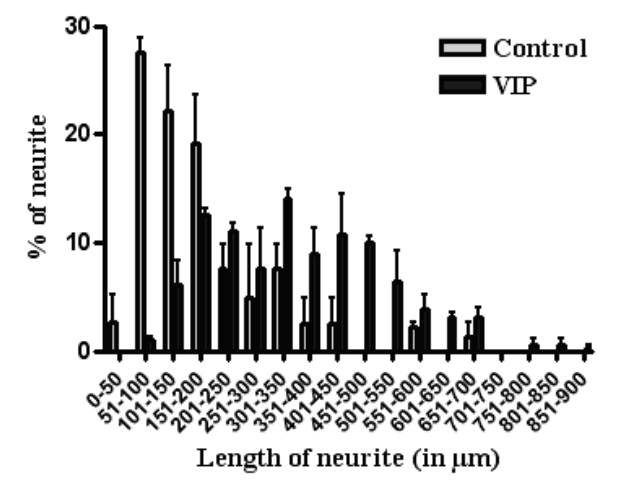

E

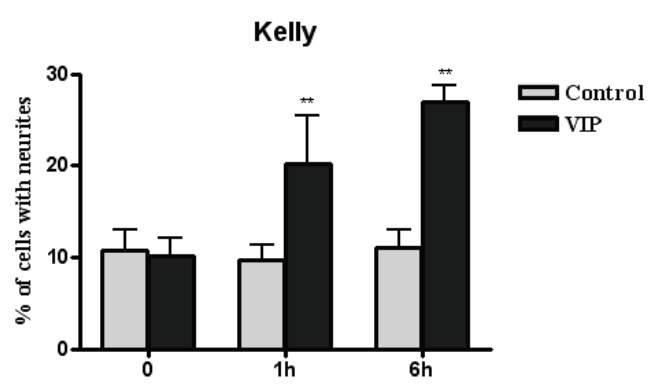

F
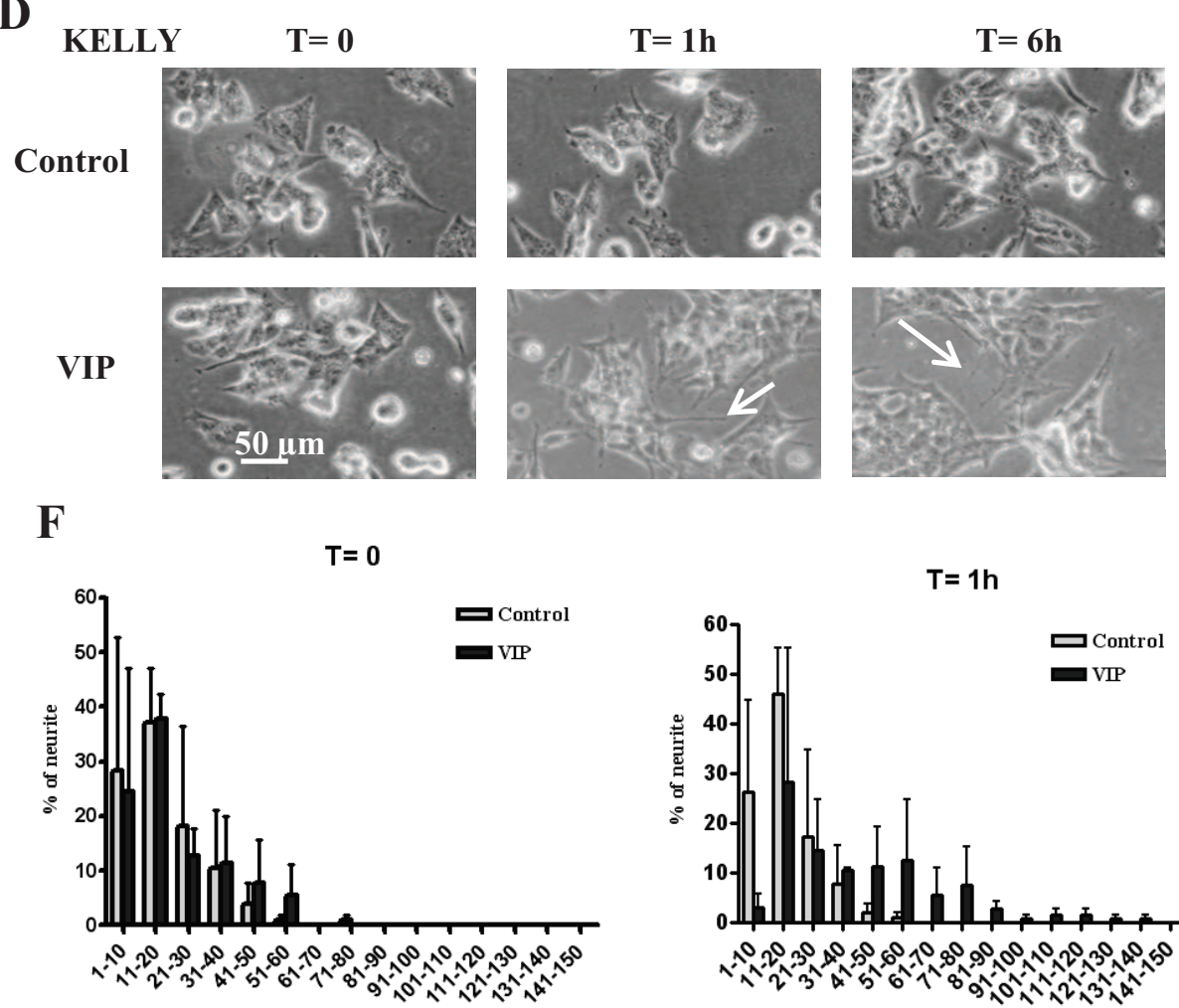

Length of neurite (in $\mu \mathrm{m}$ )
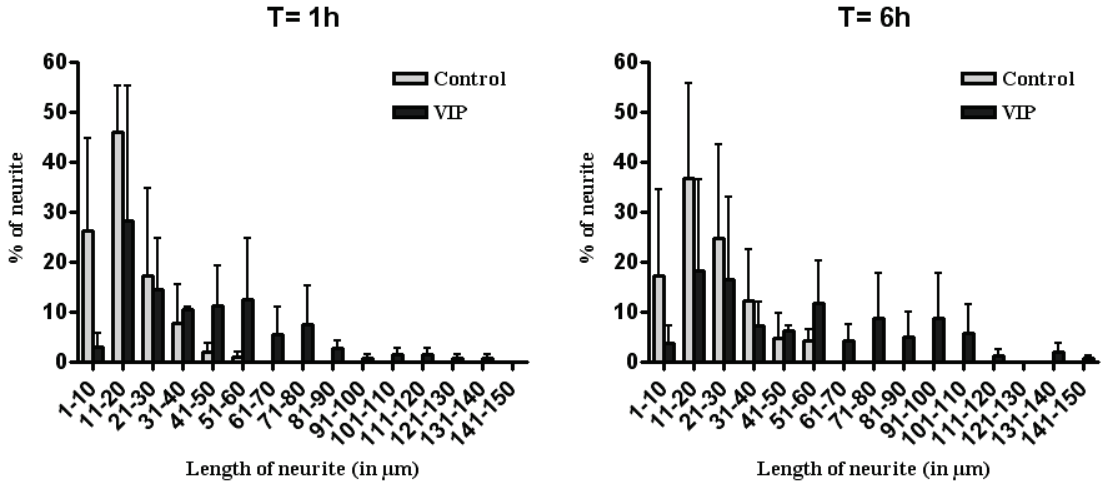
Figure 2

A

SK-N-DZ

$\frac{1 h}{C \quad V} \frac{3 h}{C \quad V} \quad \frac{6 h}{C \quad V} \quad \frac{24 h}{C \quad V}$

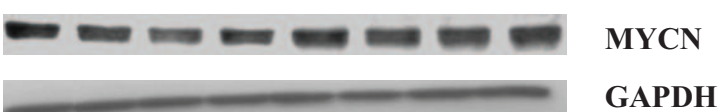

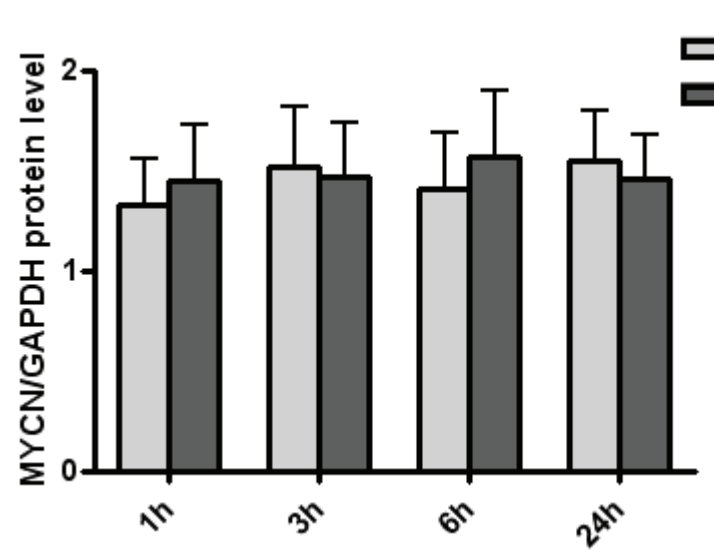

C
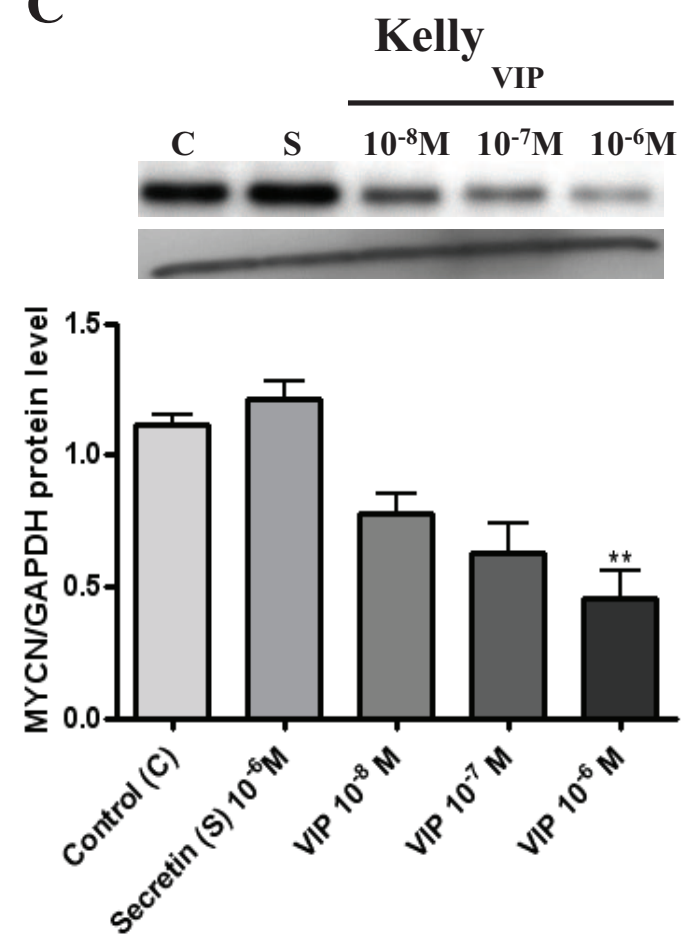

B

Kelly

$\frac{1 h}{C V} \frac{3 h}{C V} \frac{6 h}{C \quad V} \frac{24 h}{C V} \frac{48 h}{C V} \frac{72 h}{C V}$

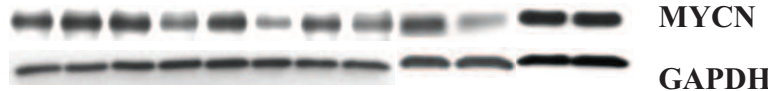

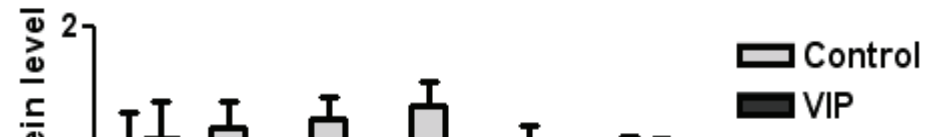

D

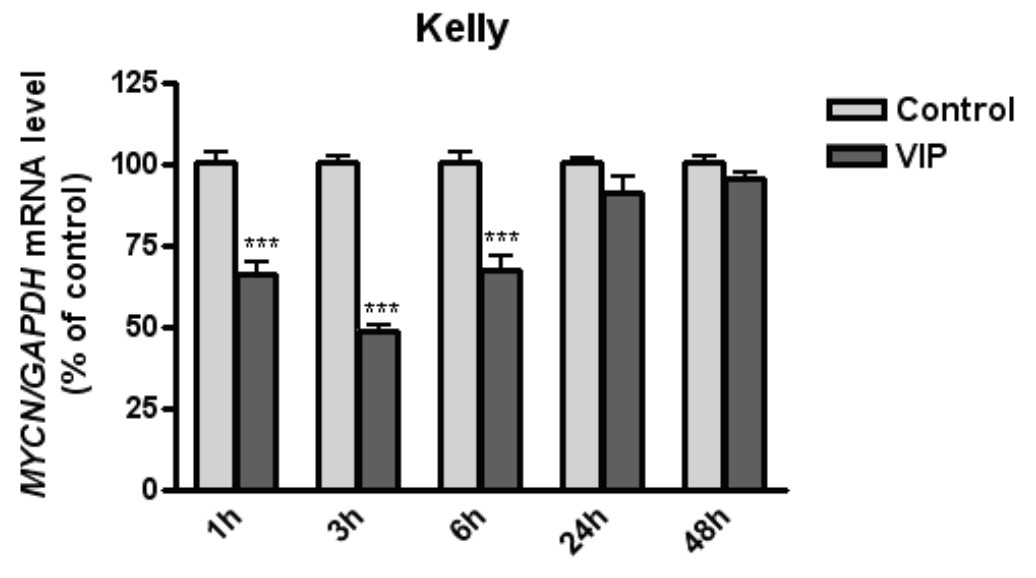


Figure 3

A

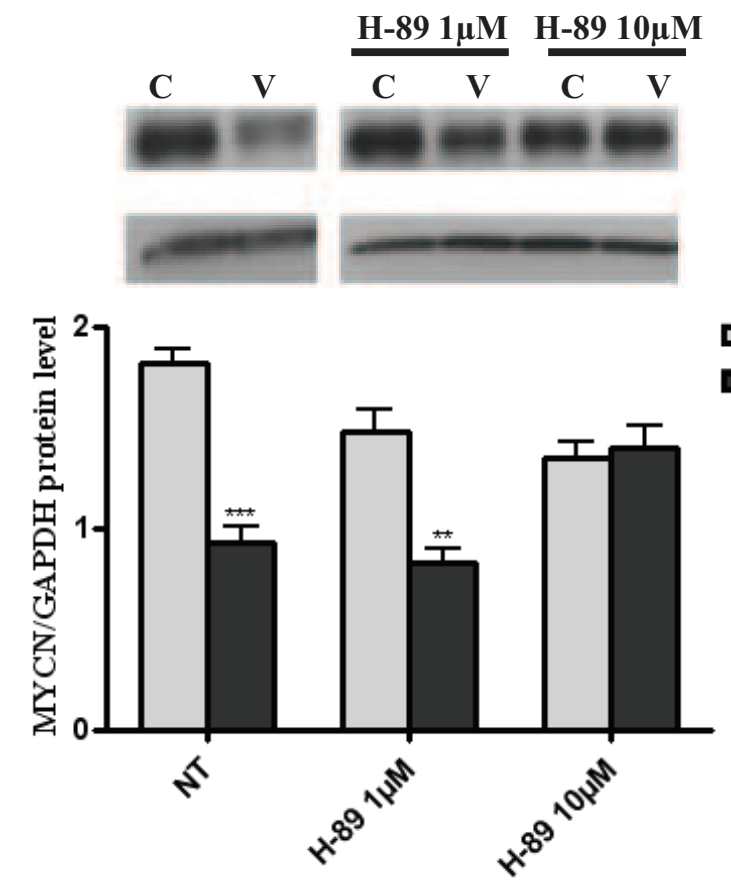

C

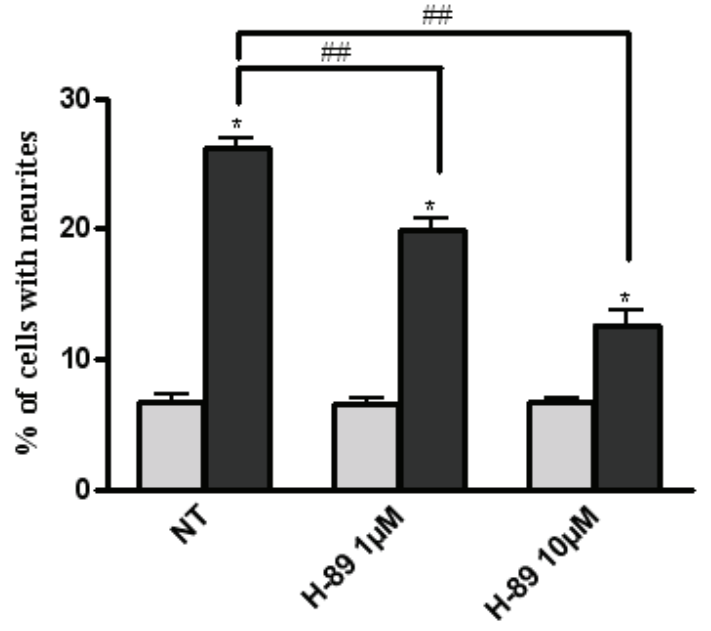

B

IMR-32

MYCN

GAPDH

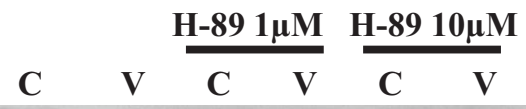

MYCN

GAPDH

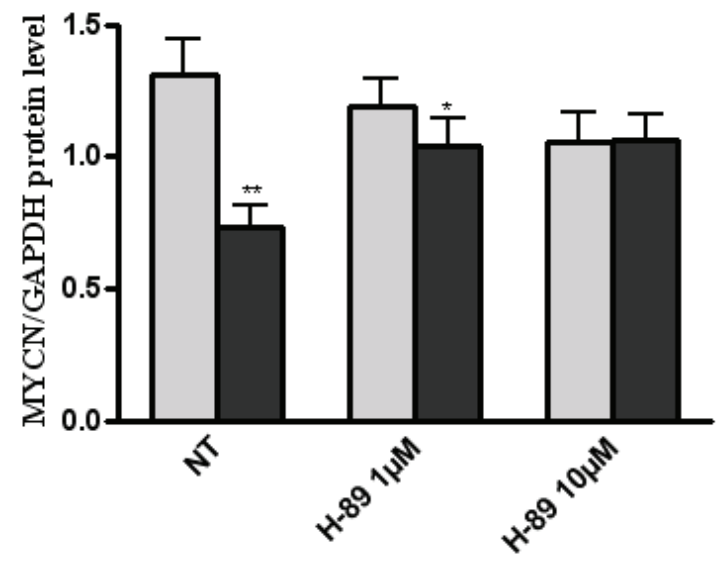

D

IMR-32

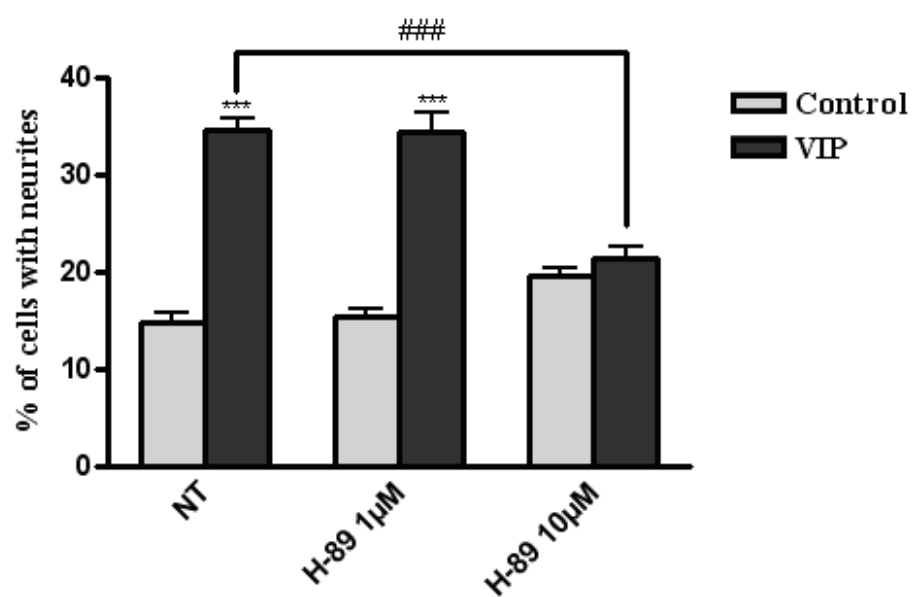


Figure 4

A

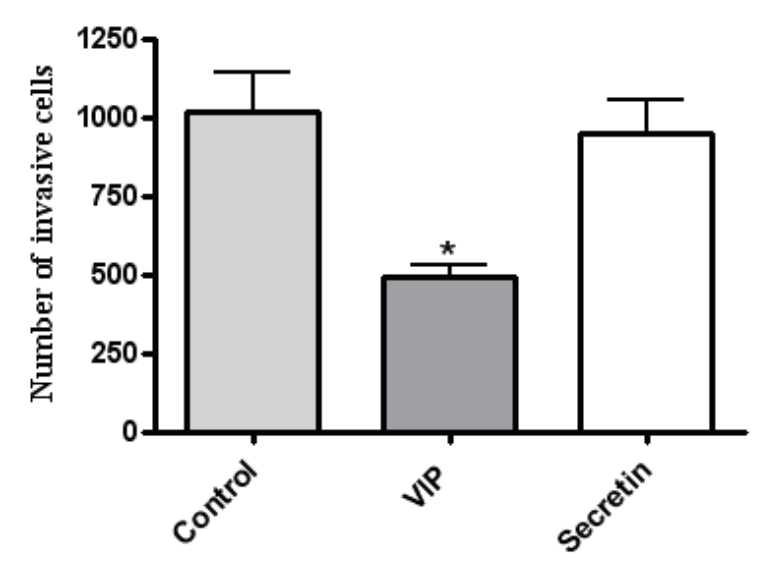

C
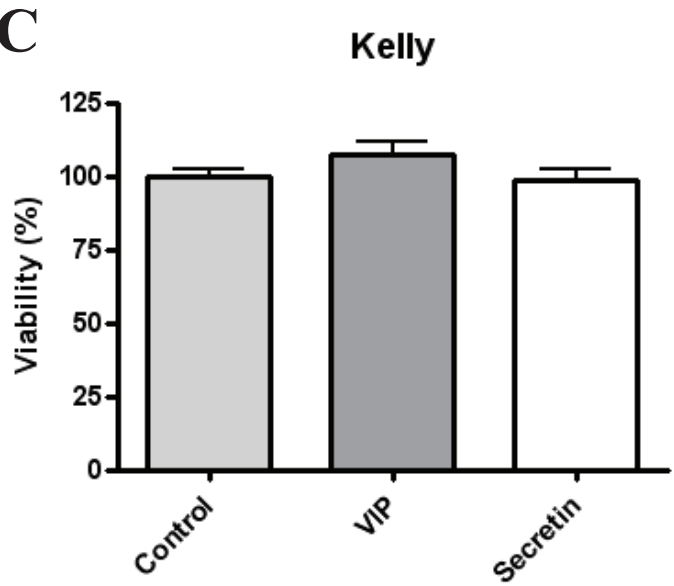

B

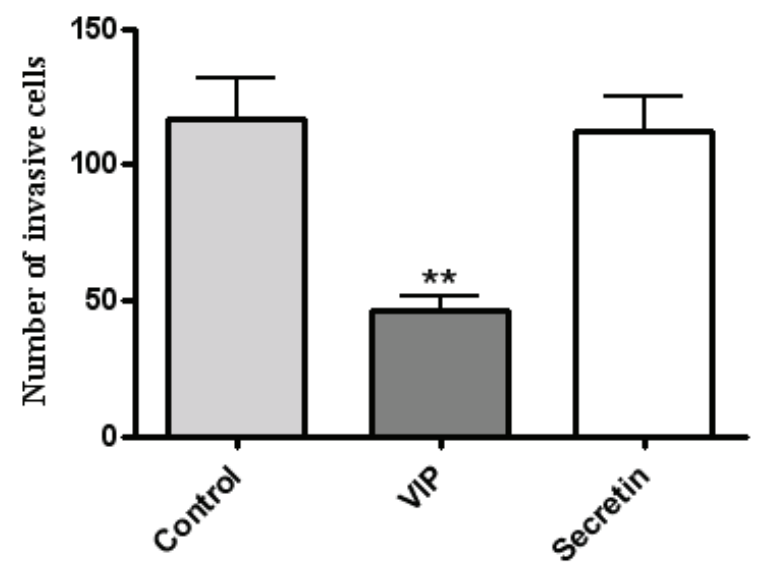

D

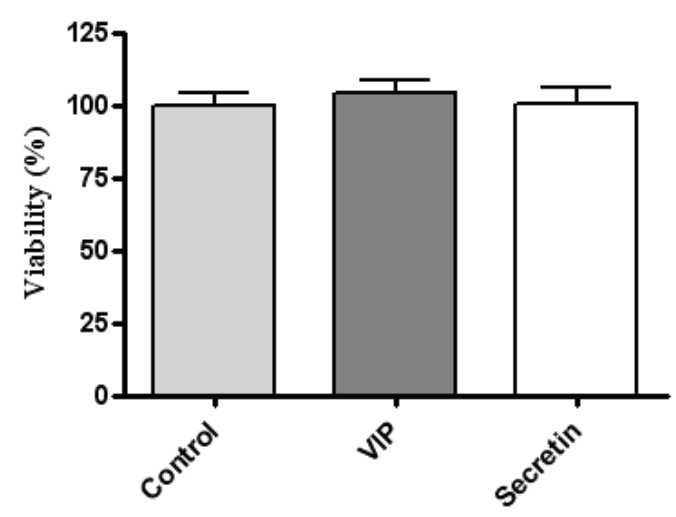


Figure 5

A

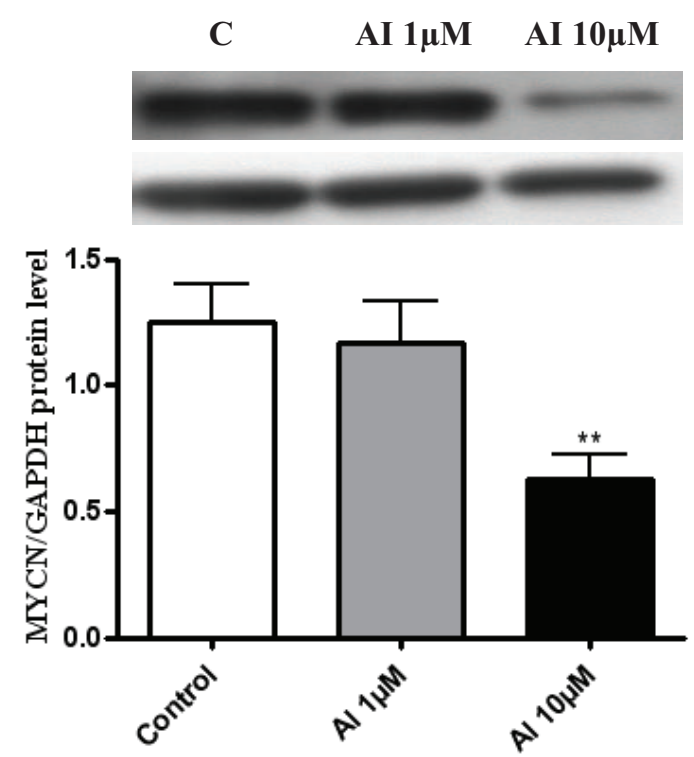

B VIP $10^{-6} \mathrm{M}$
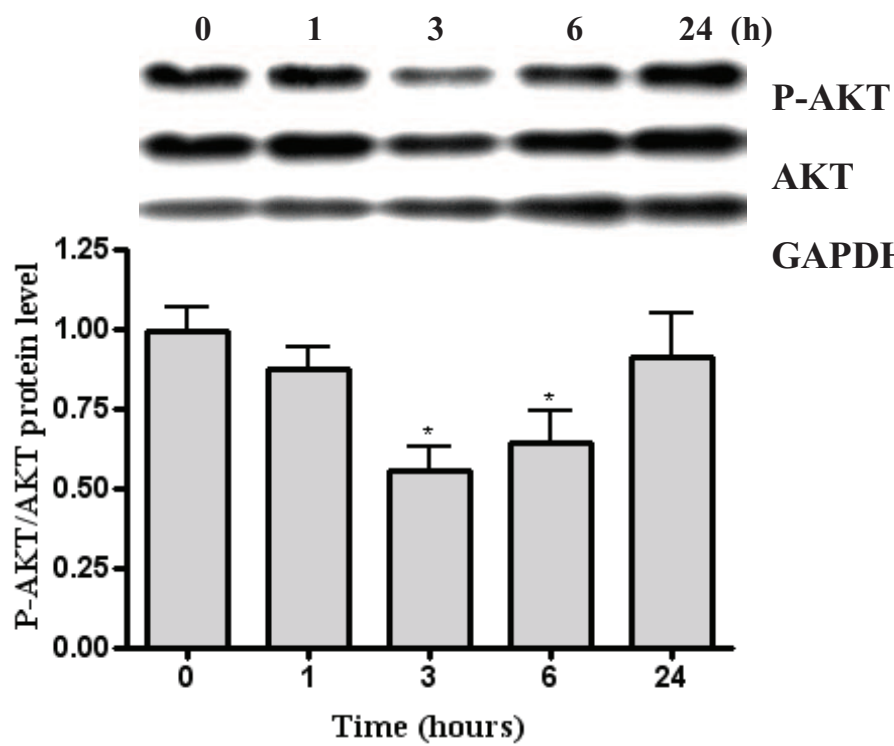

GAPDH

C
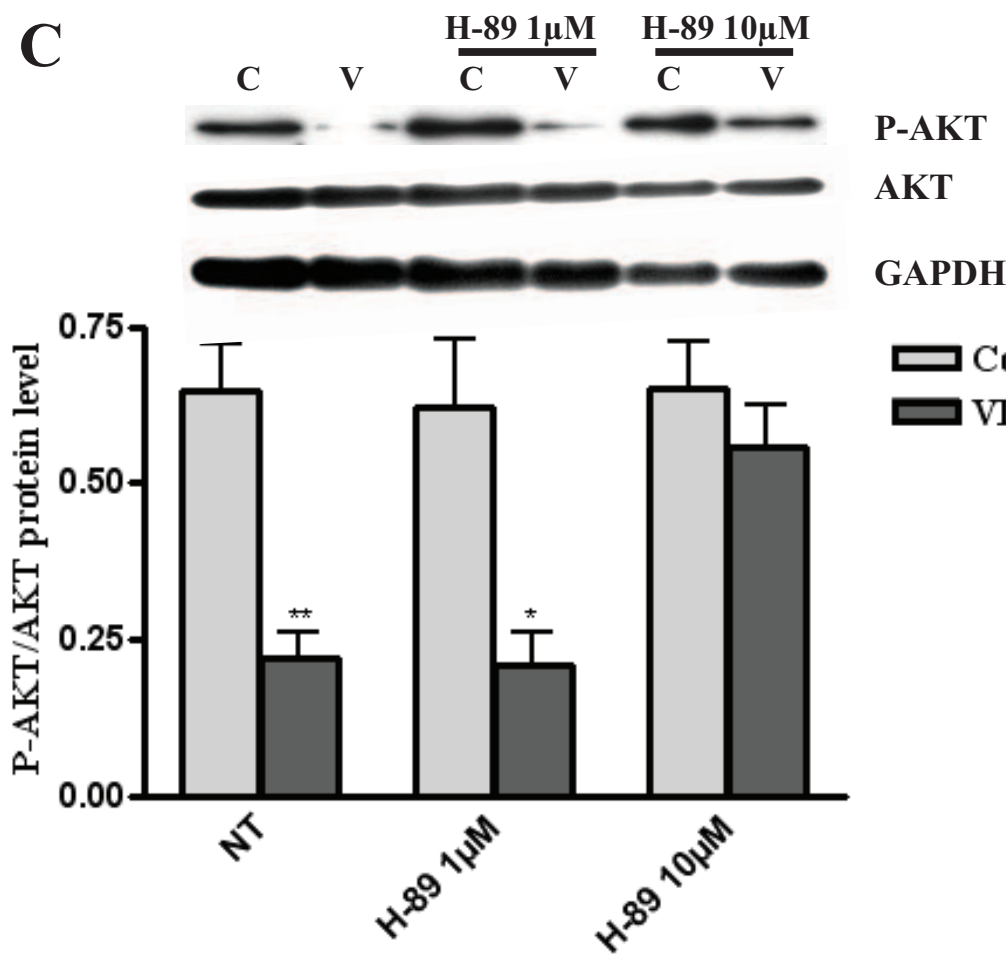

GAPDH

Control

VIP 
Figure 6
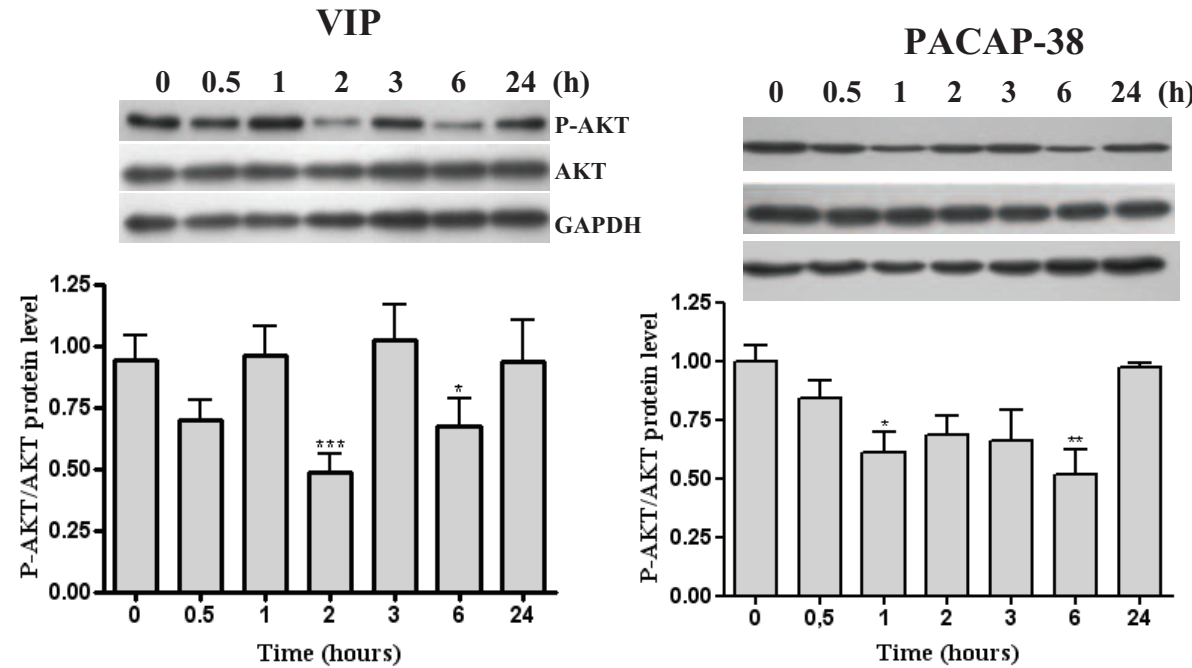

PACAP-27
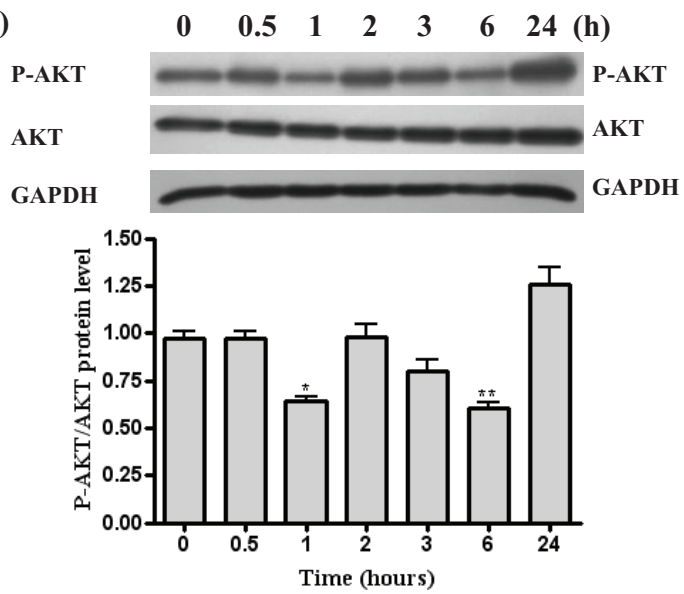

[Ala $\left.{ }^{7}\right]$ PACAP27

$\begin{array}{llllllll}0 & 0.5 & 1 & 2 & 3 & 6 & 24 & \text { (h) }\end{array}$

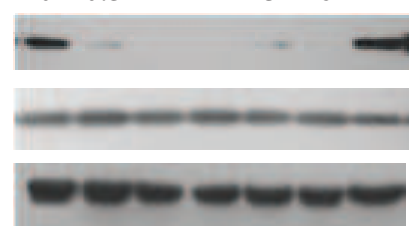

P-AKT

AKT

GAPDH
[Hyp $\left.{ }^{2}\right]$ PACAP27

$\begin{array}{llllllll}0 & 0.5 & 1 & 2 & 3 & 6 & 24 & \text { (h) }\end{array}$
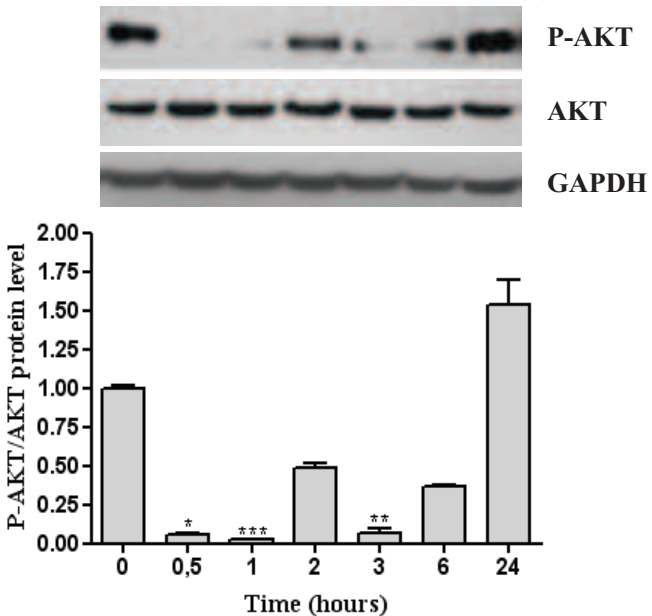

Acetyl[Phe(I) ${ }^{6}$, NLe $\left.{ }^{17}\right]$ PACAP27

$\begin{array}{llllllll}0 & 0.5 & 1 & 2 & 3 & 6 & 24 & \text { (h) }\end{array}$

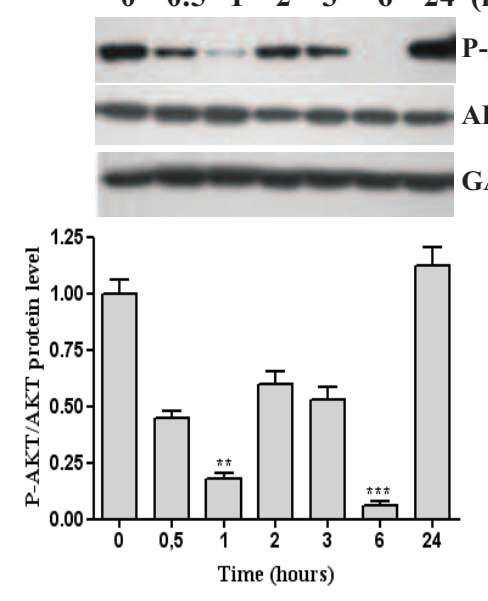

Acetyl-PACAP27-propylamide

$\begin{array}{llllllll}0 & 0.5 & 1 & 2 & 3 & 6 & 24 & \text { (h) }\end{array}$

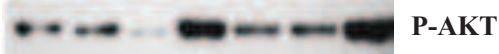

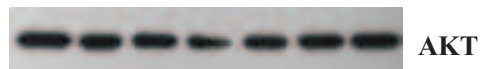

APDH

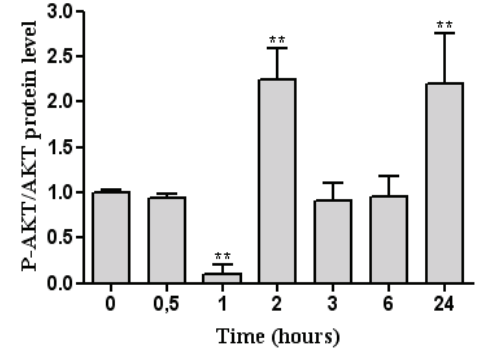

N-acetyl[Ala15, Ala20]-PACAP38-propylamide
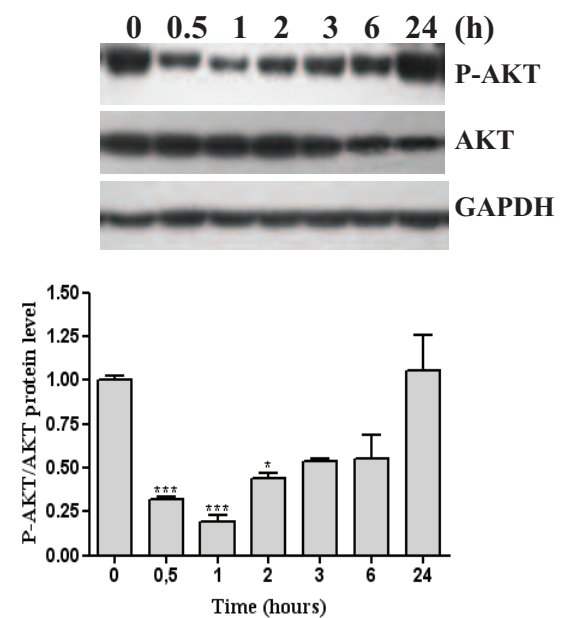
A

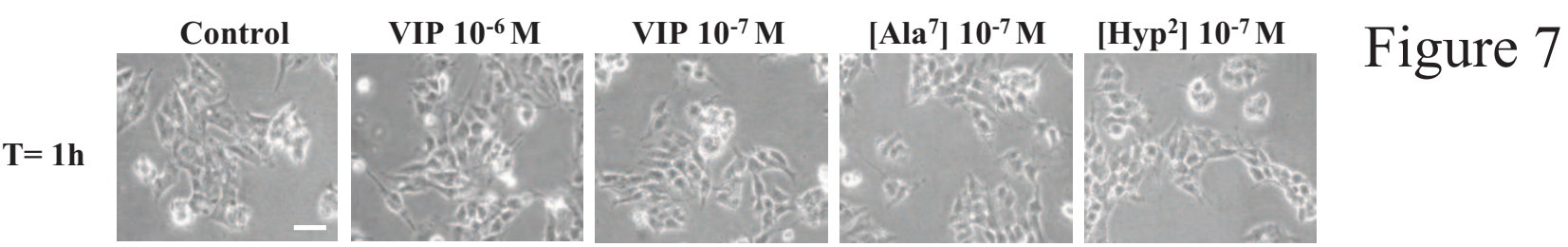

$T=6 h$

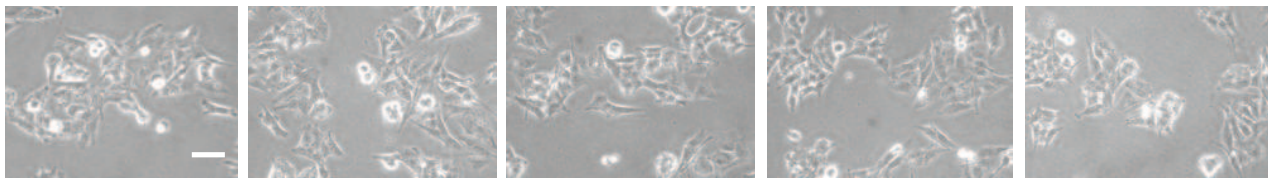

$\mathbf{T}=\mathbf{2 4 h}$

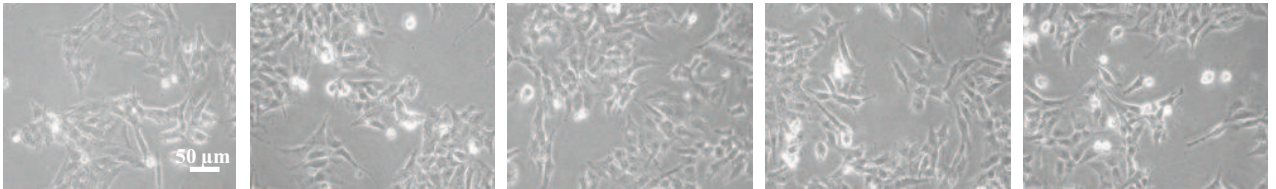

B

C
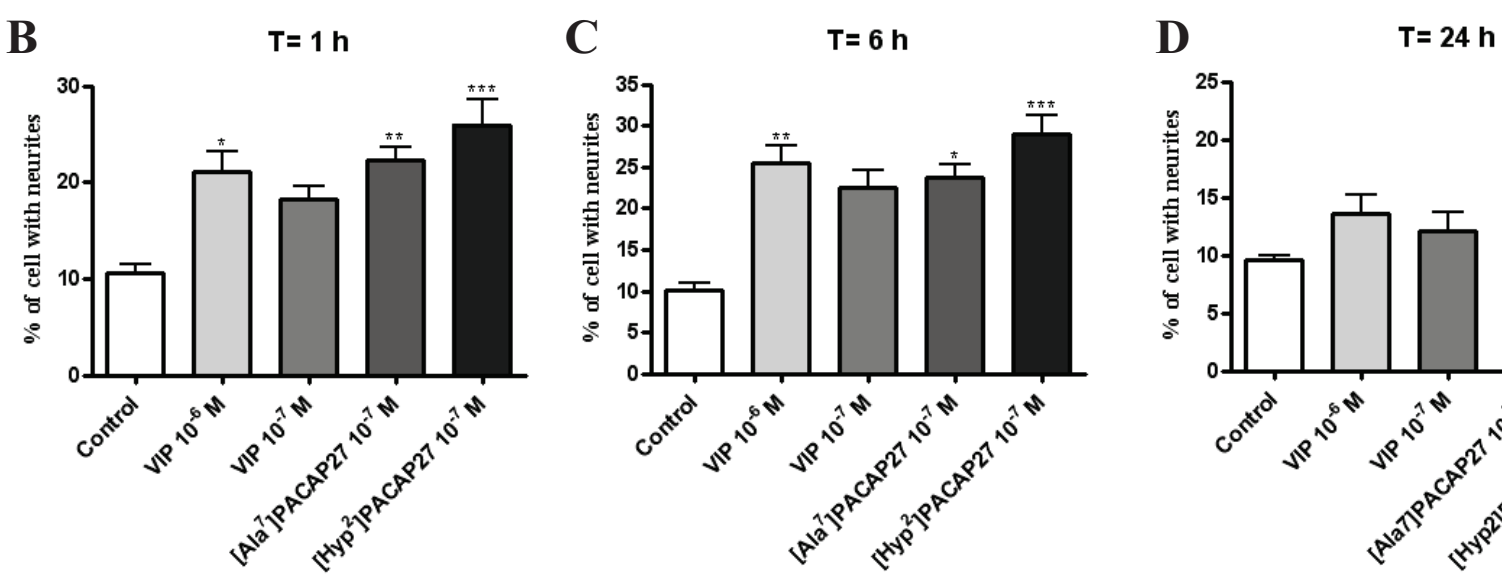

E
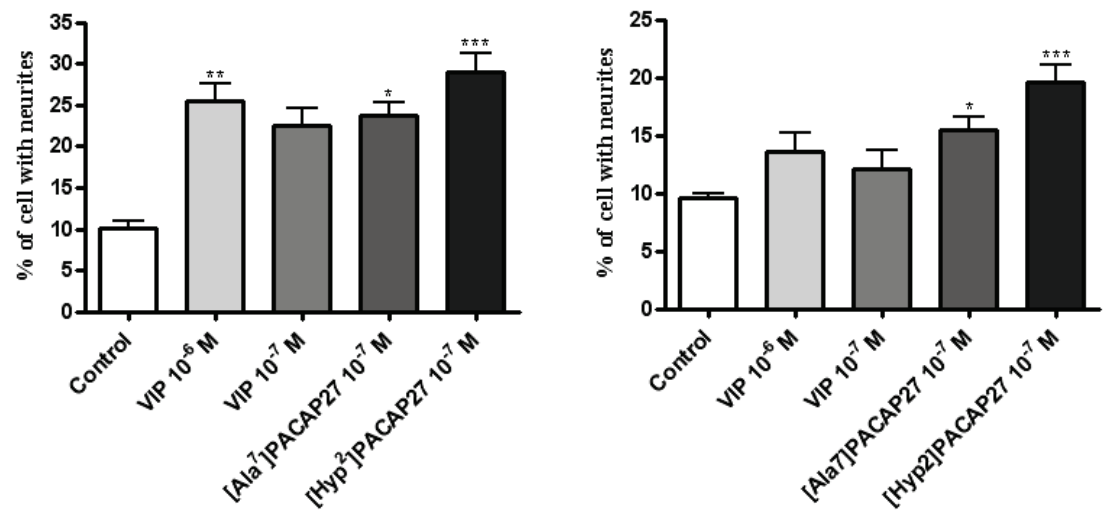

F

[Hyp $\left.{ }^{2}\right]$ PACAP27
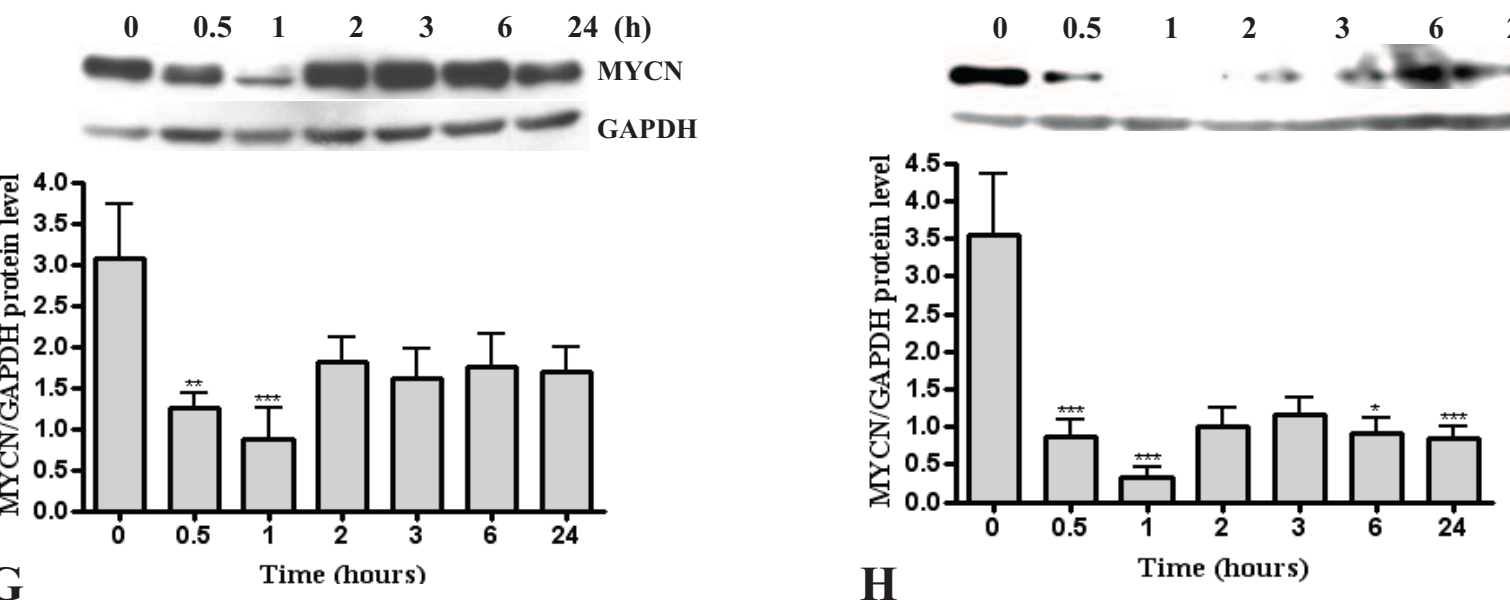

G

H
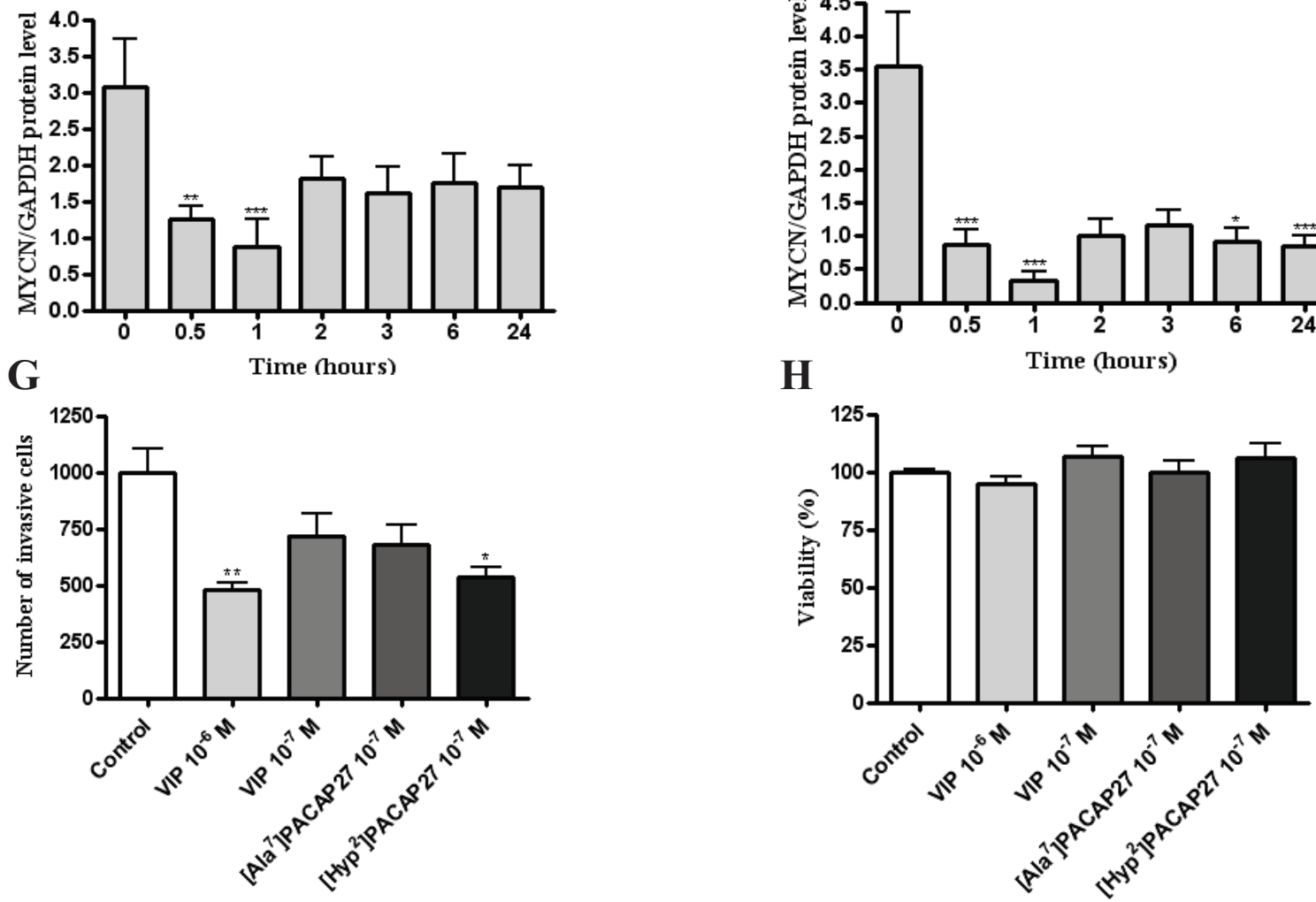

24 (h)

GAPDH 